\title{
Gust Response Sensitivity Characteristics of Very Flexible Aircraft
}

\author{
Matthew J. Dillsaver ${ }^{1}$, Carlos E.S. Cesnik ${ }^{2}$, Ilya V. Kolmanovsky ${ }^{3}$ \\ The University of Michigan, Ann Arbor, Michigan, 48109, USA
}

\begin{abstract}
This paper studies the effect of varying structural stiffness parameters on the gust response of a very flexible aircraft (VFA). Twelve different aircraft models, as well as the baseline model, are subjected to a temporally and spatially distributed gust of varying durations. The open loop response of the models is examined as a function of different natural frequencies and frequency ratios. Linear models are extracted from the nonlinear data using system identification. These linear models are then examined to determine their stability and controllability properties. A Linear Quadratic Gaussian (LQG) controller is used to determine the closed loop response of the models to a pitch step command in the presence of gust. Finally, the models are given a $0^{\circ}$ pitch command in order to examine the ability of the LQG controller to maintain level flight while encountering gust.
\end{abstract}

\section{Introduction}

A $S$ aircraft designers increasingly pursue high performance, low cost Unmanned Aerial Vehicle (UAV) solutions, Very Flexible Aircraft (VFA) characteristics are becoming more prominent . One type of particular interest is the High Altitude, Long Endurance (HALE) aircraft which is of interest for both military and civilian uses, In order to optimize flight performance in HALE flight, aircraft are normally built with relatively long and slender high-aspect ratio wings, allowing for high lift-to-drag ratios, thereby maximizing aerodynamic efficiency. These mission requirements lead HALE aircraft designers to minimize weight to the greatest extent possible, often resulting in a low structural weight fraction, and causing HALE aircraft to be very flexible, with large wing deformations possible during flight. Additionally, VFA tend to exhibit an overlap in the lowest elastic mode frequencies and the rigid-body flight dynamic frequencies. ${ }^{1}$

These VFA attributes can make the aircraft very susceptible to external disturbances, such as atmospheric gust. This was apparent in June 2003 on the Aerovironment Helios aircraft. After encountering unexpected turbulence the aircraft entered into a high dihedral configuration. As a result, the aircraft began an unstable, diverging pitch oscillation with airspeed excursions doubling on every oscillation. After the design airspeed was eventually exceeded, the aircraft broke apart and fell into the Pacific Ocean. ${ }^{2}$ The nonlinearities present as well as the frequency overlap seen in VFA lead to difficulties in modeling, simulation and control. One of the recommendations from the Helios mishap report was to, "develop more advanced, multi-disciplinary (structures, aeroelastic, aerodynamics, atmospheric, materials, propulsion, controls, etc.) time-domain analysis methods appropriate to highly-flexible, morphing vehicles."

Recently, there has been much research into the modeling and dynamics of VFA. Patil, Hodges and Cesnik ${ }^{3}$ studied VFA flight dynamics and aeroelasticity, and showed that the large deformations of flexible wings can cause significant changes in aircraft dynamics. Additionally, they showed that the wing shape of VFA can vary greatly across differing flight conditions. Su and Cesnik $^{4}$ demonstrated that aeroelastic analysis of VFA must be accomplished at the actual trimmed shape of the aircraft for the given flight conditions. Palacios and Cesnik ${ }^{5}$ compared displacement-based, strain-based, and geometrically nonlinear beam models and determined that a combination of a displacement-based method for the fuselage and tails and a strain-based or geometrically nonlinear beam model for the flexible wing provides the best solution. Shearer and Cesnik ${ }^{6}$ used a representative HALE aircraft model to show that a rigidized aircraft model is not sufficient to capture the flight dynamics of VFA. Furthermore, they established that a linearized model is sufficient for simple, symmetric maneuvers, but a full nonlinear model is needed for more complex maneuvers.

\footnotetext{
${ }^{1}$ Captain, US Air Force, Ph.D. Candidate (dills@umich.edu), Dept of Aerospace Engineering, Member, AIAA.

${ }^{2}$ Professor (cesnik@umich.edu), Dept of Aerospace Engineering, Fellow, AIAA.

${ }^{3}$ Professor (ilya@umich.edu), Dept of Aerospace Engineering, Member, AIAA.
} 
There has been little research in the sensitivity of VFA gust response to variations in aircraft parameters. Layton $^{7}$ studied the effect of varying structural and geometric properties on the gust response of a finite span wing. He found that increasing the bending-to-torsional stiffness ratio increases the root mean square (RMS) of the pitch angle. There is a much larger body of work on control of VFA in the presence of gust. The authors of Ref. [8] showed that an LQG controller can be used effectively to reduce the gust response of a small VFA model and that a reference governor can be augmented to enforce hard limits on the wing curvature while tracking a pitch angle command. Gibson, Annaswamy, and Lavretsky ${ }^{9}$ demonstrated that an adaptive LQG/LTR controller performed better than a linear LGQ/LTR for stabilizing a VFA undergoing large dihedral excursions.

This paper presents a study of the sensitivity of a VFA aircraft model to the variations in structural stiffness parameters. Various open loop and closed loop gust response metrics are compared, and stability and controllability properties of the different models are examined. The results are presented as a function of various frequency ratios, as well as a function of the frequencies themselves.

\section{Background}

In this section, we review the gust and aircraft modeling fundamentals, as well as the control concepts which are subsequently used in our analysis.

\section{A. Gust Modeling}

There are multiple approaches to modeling wind gust for simulation purposes. The two most popular approaches are based on discrete or stochastic methods. In the stochastic models, such as the von Karman model and the Dryden model, the gust is represented as a stationary, random, Gaussian process. The power spectral density of the gust is then determined based on turbulence field properties, such as the turbulence scale and RMS gust velocity. ${ }^{10}$ The discrete gust method assumes the gust field exhibits a one-minus-cosine distribution. For example, the Federal Aviation Regulations (FAR) Part $23^{11}$ uses a discrete model given by:

$$
U=\frac{U_{d e}}{2}\left[1-\cos \left(\frac{2 \pi s}{25 C}\right)\right]
$$

where $U$ is the gust velocity, $s$ is the distance penetrated into the gust, $C$ is the mean geometric chord and $U_{d e}$ is the derived gust velocity which varies from 38 to $66 \mathrm{ft} / \mathrm{s}$, depending on altitude, aircraft category and air roughness. ${ }^{11}$ The Defense Advanced Research Project Agency (DARPA) defined a discrete, non-uniform spanwise gust model for use on the Vulture II program. ${ }^{12}$ The model is based on a one-minus-cosine distribution with a sinusoidal spanwise variation, and considers vertical gust velocity only. The single-amplitude gust velocity is given by:

$$
U_{S A}=\frac{U_{d e}}{2}\left(\frac{b}{2 L}\right)^{1 / 3}
$$

where $b$ is the aircraft span, and $\mathrm{L}$ is the characteristic length of reference gust from von Karman PSD model. The placement of the spanwise distribution is determined in such a way as to cause the largest spar root bending moment. ${ }^{12}$

\section{B. Aircraft Modeling}

The aircraft is modeled using the University of Michigan Nonlinear Aeroelastic Simulation and Toolbox (UM/NAST). UM/NAST implements a strain-based elastic formulation and is capable of simulating rigid body, linearized and nonlinear aircraft dynamics. ${ }^{13}$ The unsteady aerodynamic forces are calculated using the finite state inflow method developed by Peters and Johnson. ${ }^{14}$

A strain-based formulation of the nonlinear equations of motion for flexible aircraft based upon the principle of virtual work used in this study is given by: ${ }^{6}$ 


$$
\begin{gathered}
M_{F F} \ddot{\varepsilon}=-M_{F B} \dot{\beta}-C_{F F} \dot{\varepsilon}-C_{F B} \beta-K_{F F} \varepsilon+R_{F} \\
M_{B B} \dot{\beta}=-M_{B F} \ddot{\varepsilon}-C_{B B} \beta-C_{B F} \dot{\varepsilon}+R_{B} \\
\dot{\zeta}=-\frac{1}{2} \Omega_{\zeta} \zeta \\
\dot{p_{b}}=\left[\begin{array}{cc}
C^{B G} & 0
\end{array}\right] \beta \\
\dot{\lambda}=F_{1} \ddot{q}+F_{2} \dot{q}+F_{3} \lambda
\end{gathered}
$$

where $M$ is the generalized mass matrix, $C$ is the structural damping matrix, $K$ is the stiffness matrix, $R$ represents the generalized forces, the subscript $F$ denotes flexible terms, the subscript $B$ denotes terms in the body-fixed coordinate system, $\varepsilon$ is the strain vector containing the four strain elements (extensional strain, twist of the beam reference line, and bending about the $y$ and $z$ axis), $\beta$ is the rigid body velocity vector containing three translational and three rotational velocities, $\zeta$ represents the four quaternions, $p_{b}$ is a position vector for the body, $C^{B G}$ is a translation matrix for the body fixed coordinate system to the inertial system. The last equation calculates the unsteady aerodynamic forces and moments.

In this formulation two coordinate systems are used which are shown in Figure 1. The global, or G, frame is an inertial frame fixed to the ground. The rigid body velocities are calculated using the body, or B, frame centered at the origin. Note that the origin is an arbitrarily defined point on the body and is, in general, not at the center of gravity. ${ }^{1}$ The positive $\mathrm{x}$-axis of the $\mathrm{B}$ frame points out the right wing, the positive $\mathrm{y}$-axis is in the direction of forward flight and the positive $\mathrm{z}$-axis is in the up direction.

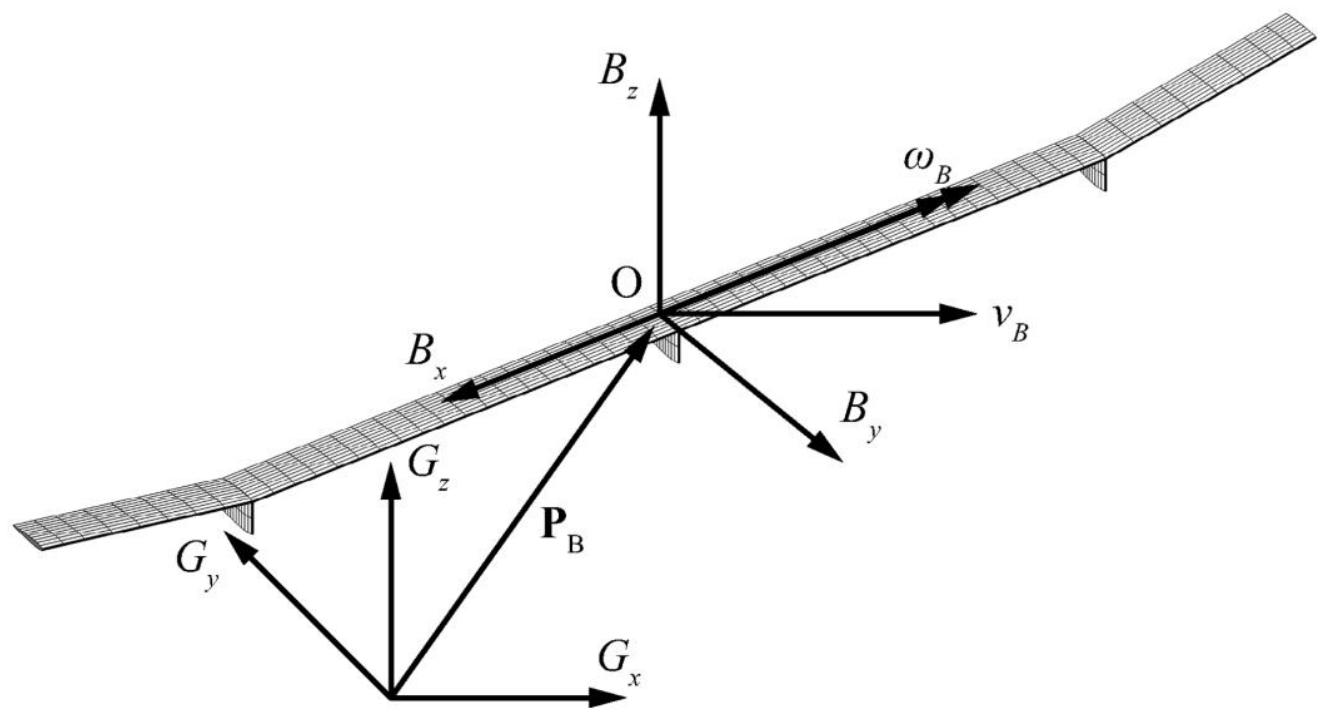

Figure 1. Coordinate systems used.

\section{Stability and Controllability}

We use standard notations and criteria for stability. The equilibrium point, $\mathrm{x}_{\mathrm{e}}$, of the system show in Eq. (4) is said to be stable in the sense of Lyapunov (ISL) if the following holds: for all $\varepsilon>0$, there exists a $\delta>0$, such that $\left\|x_{0}-x_{e}\right\|<\delta$ implies that $\left\|x(t)-x_{e}\right\|<\varepsilon$ for all $\mathrm{t} \geq 0$. If an equilibrium point is stable and additionally $\lim _{t \rightarrow \infty}\left\|x(t)-x_{e}\right\|=0$, then it is said to be asymptotically stable. ${ }^{15}$ This means that if a trajectory starts close to a stable equilibrium point, it will stay close. Alternatively, if a trajectory starts close to an asymptotically stable equilibrium point, it will not only stay close to the equilibrium point, but as time goes to infinity it will approach that point. Consider a linear, time invariant system of the form:

$$
\begin{gathered}
\dot{x}=A x+B u \\
y=C x+D u \\
x(0)=x_{0}
\end{gathered}
$$


where $x$ is the state vector and $u$ is the control input. Then the equilibrium is stable if, and only if, all eigenvalues of $A$ have non-positive real parts and that all zero eigenvalues possess a full set of eigenvectors. The equilibrium point is asymptotically stable if, and only if, all eigenvalues of $A$ have strictly negative real parts. ${ }^{15}$

The states of the system in Eq. (4) are said to be controllable if there exists a control, $u$, such that an arbitrary final state can be achieved for an arbitrary initial state over a given time interval. ${ }^{16}$ The system in Eq. (4) is said to be completely controllable if all the states are controllable. One test for controllability is that:

$$
W=\int_{0}^{\infty} e^{A \tau} B B^{T} e^{A^{T} \tau} d \tau>0
$$

where the greater than sign signifies positive definiteness, the superscript $T$ indicates the matrix transpose and $W$ is the controllability gramian. Many texts present the condition in Eq. (5) slightly differently, stating that $W$ must be non-singular. The two conditions are equivalent because the gramian is always positive semi definite, therefore if $W$ is positive definite that implies that $W$ is nonsingular. ${ }^{17}$ In many cases, the full state vector, $x$, is not available for control, but rather only a smaller set of outputs is available. Therefore, the notion of output controllability can be useful. Similar to the definition of state controllability, an output is controllable if there exists a control such that an arbitrary final output can be achieved from an initial output at the origin in finite time. A test for output controllability is that the output controllability gramian defined as $W_{\text {output }}=C W C^{T}$ is positive definite.

One way of determining the relative controllability of a system is to calculate the minimum control effort required to drive a system from the origin to a specified final state, $x_{f}$. The minimum control effort, assuming free arrival time, can be found using the following relation: ${ }^{18}$

$$
E=x_{f}^{T} W^{-1} x_{f}
$$

If one is interested in driving the system from a zero output to a final output $y_{f}$, the output control effort can be defined as:

$$
E_{\text {output }}=y_{f}^{T} W_{\text {output }}^{-1} y_{f}
$$

which is a useful measure of relative controllability in situations when states lose their physical meaning (e.g. after model reduction or through system identification).

\section{Linear Quadratic Gaussian Control}

The Linear Quadratic Gaussian (LQG) controller is a broadly accepted method of aircraft control. The LQG allows the designer to trade off regulation performance and control effort, while taking into account process and measurement noise. ${ }^{19}$ The LQG is essentially the combination of a Kalman filter for optimal estimation and a Linear Quadratic Regulator (LQR) providing optimal control. The use of the Kalman filter allows for the estimation of the full state vector, based on the outputs, to be fed into the LQR. The separation principle allows the Kalman filter and the LQR to be designed independently. A block diagram for a typical LQG controller is shown in Figure 2, where $w$ is the disturbance signal, $y$ is the vector of the measured outputs, $u$ is the control signal generated by the $\mathrm{LQR}$, and $\hat{x}$ is the state estimate produced by the Kalman filter. Refer to Ref. [8] for further details on LQG controller design and tuning. 


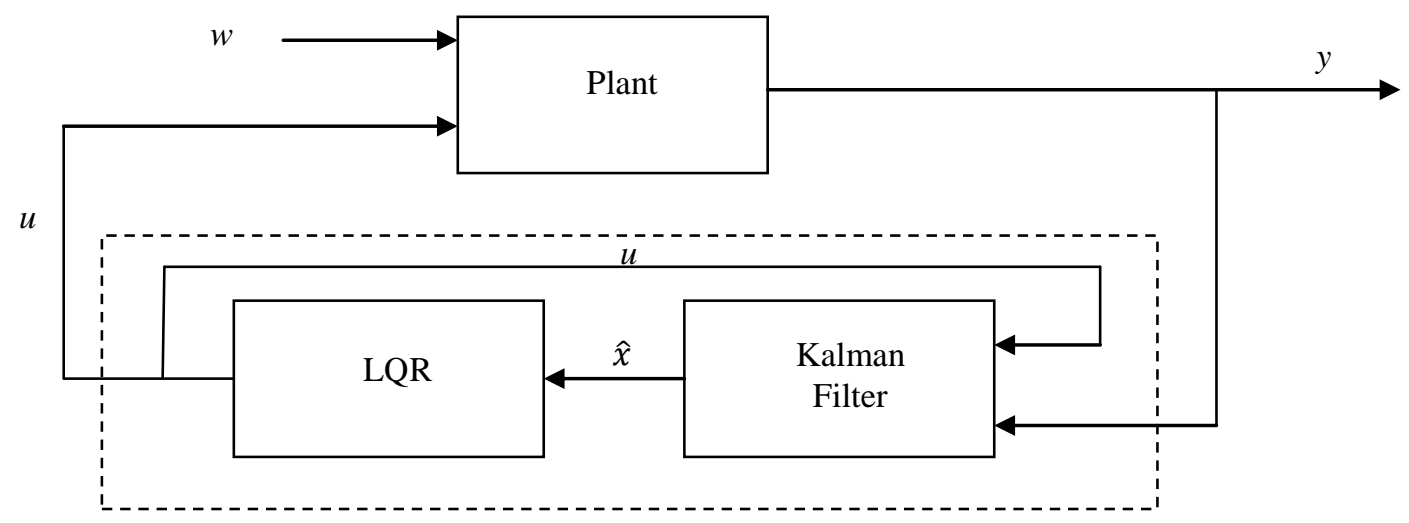

Figure 2. Generic closed loop block diagram, with LQG block represented by dotted block.

\section{Numerical Studies}

\section{A. VFA Model}

The baseline VFA model used in this study is based on the work by Patil and Hodges ${ }^{20}$ and by Su and Cesnik. ${ }^{1}$ Figure 3 shows the geometry of the flying wing model. The aircraft has a rectangular planform with a chord of $2.44 \mathrm{~m}$ and a span of $72.8 \mathrm{~m}$, with the outboard one-third of the semi-span having a dihedral of $10^{\circ}$. The aircraft has five motors mounted at even intervals across the portion of the wing with no dihedral. Additionally, the model has three pods. The two side pods have a mass of $22.7 \mathrm{~kg}$ each and the center pod has a mass of $27.23 \mathrm{~kg}$ and can also carry a payload ranging from $0 \mathrm{~kg}$ to $227 \mathrm{~kg}$.

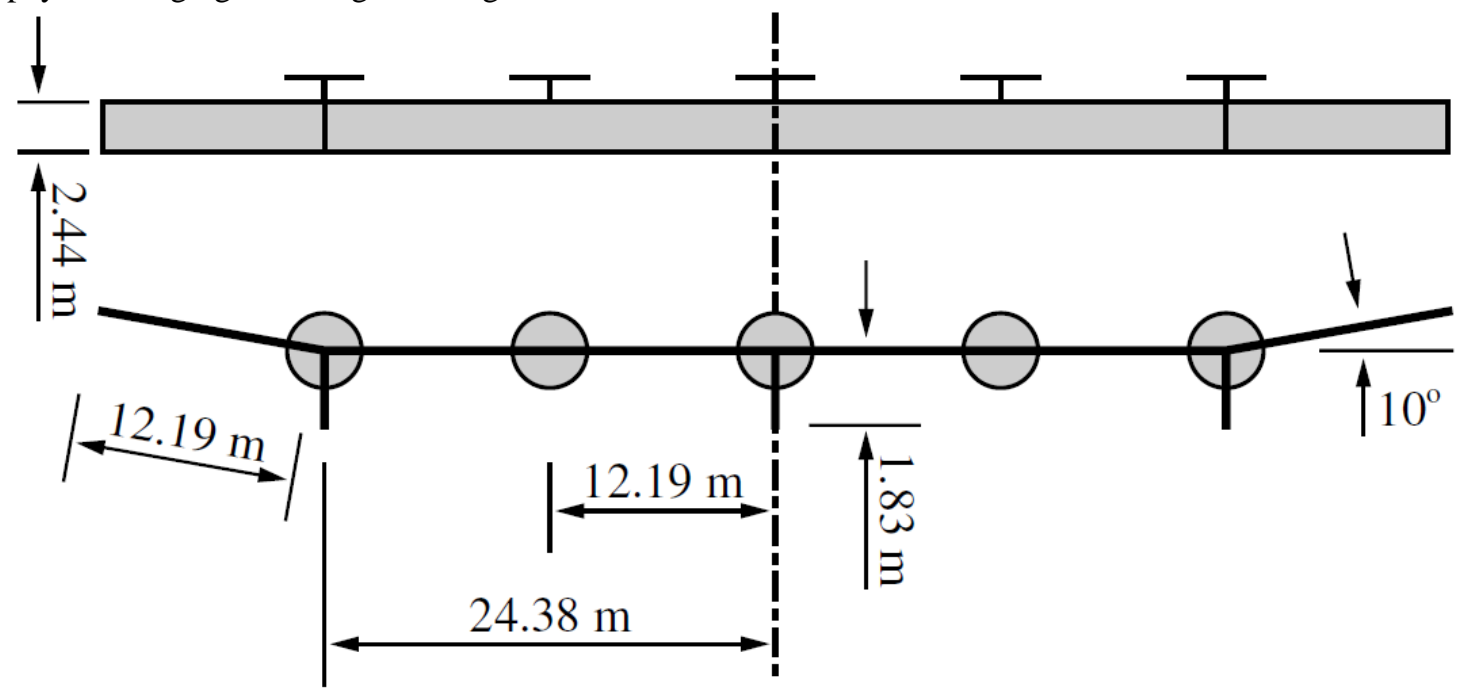

Figure 3. Aircraft Geometry. ${ }^{1}$

The aircraft is then trimmed for level flight at sea level at $12.2 \mathrm{~m} / \mathrm{s}$. The trim shape is very sensitive to the payload of the center pod. Figure 4 shows a comparison of trim shapes versus the undeformed shape for two different center pod payloads. The trimmed shape as well as the deformed wing shape of the $0 \mathrm{~kg}$ payload is shown on the left. The trim shape is virtually identical to the undeformed shape because the aircraft is span loaded. Conversely, on the right the trimmed shape for the $227 \mathrm{~kg}$ payload is shown with the undeformed shape. There is a significant difference between both the trimmed shape and the undeformed shape, as well as between the trimmed shapes of the $0 \mathrm{~kg}$ and the $227 \mathrm{~kg}$ payloads, even thought the flight conditions and wing material properties are identical. 


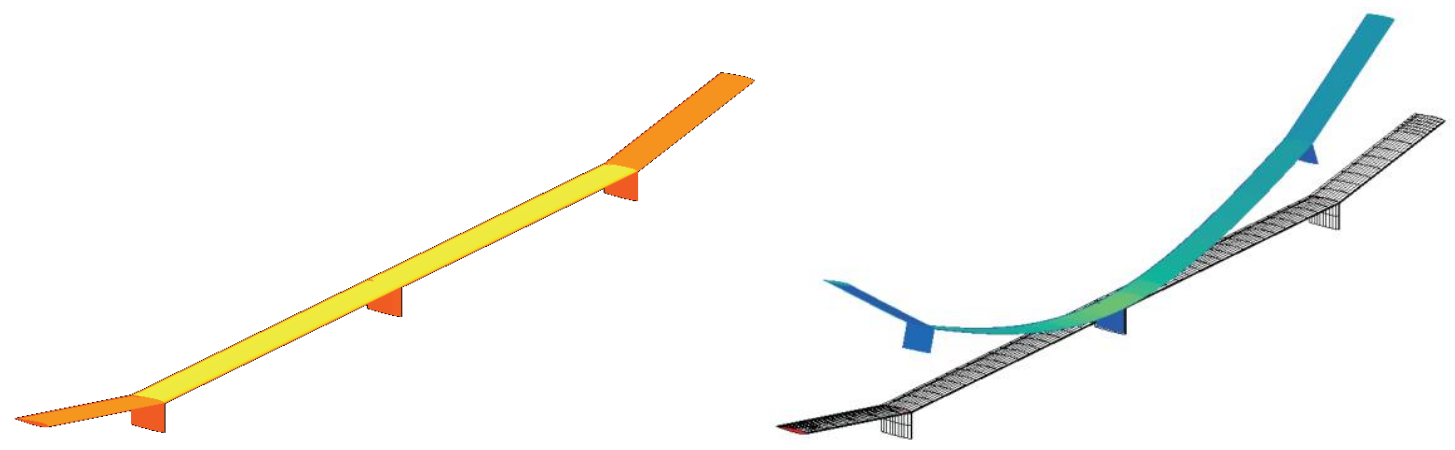

Figure 4. Comparison of trimmed shape for $0 \mathrm{~kg}$ (left) and $227 \mathrm{~kg}$ (right) center pod payloads. Undeformed geometry is shown in black mesh and trimmed shape is solid color (virtually identical for 0kg payload case).

The stability of the phugoid mode is also dependent on the trimmed shape, and therefore on the payload as well. The stability was examined by linearizing the nonlinear equations of motion about the trimmed state. This was done for varying payloads ranging from $0 \mathrm{~kg}$ to $227 \mathrm{~kg}$. A plot of the phugoid mode poles while varying the center pod payload is shown in Figure 5. As seen in Figure 5, the plot crosses the imaginary axis, and therefore the aircraft dynamics become unstable, at a payload between $140 \mathrm{~kg}$ and $150 \mathrm{~kg}$. For the study of the effects of gust, a payload of $140 \mathrm{~kg}$ was chosen because, although is close to the stability boundary, the aircraft is still statically stable.

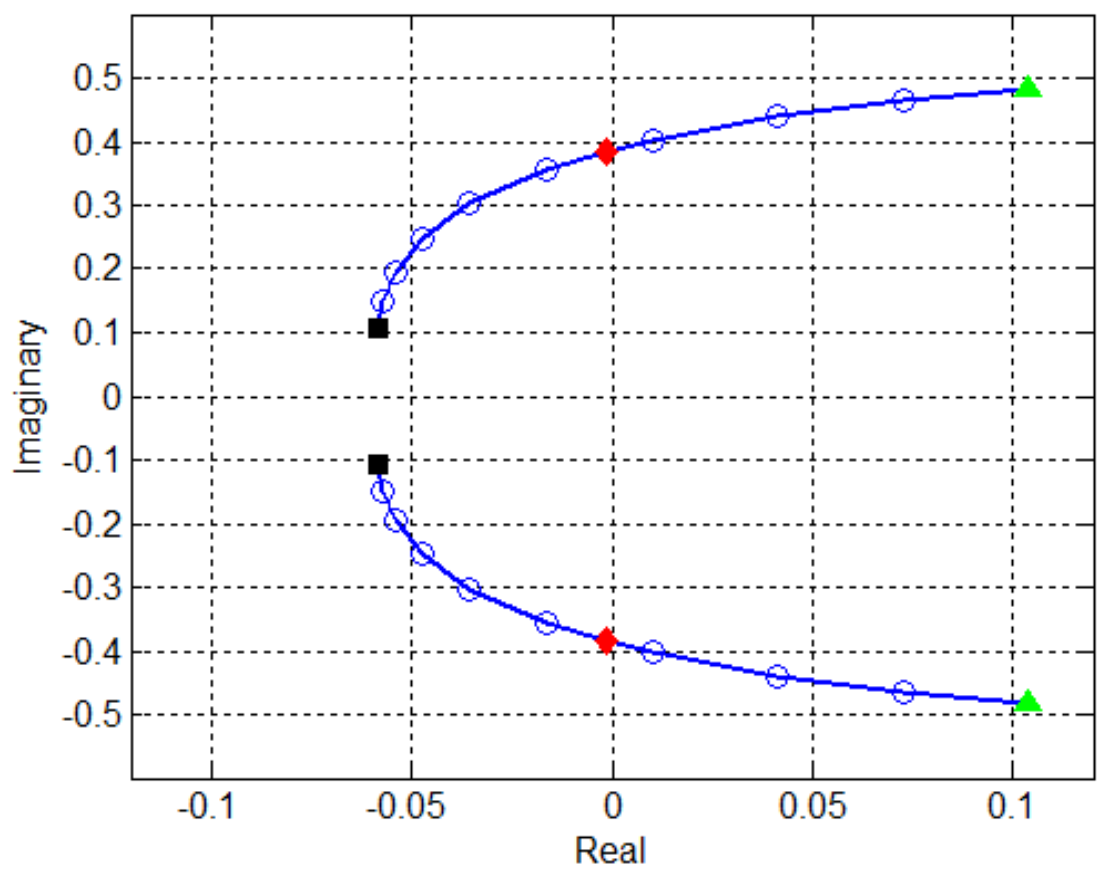

Figure 5. Plot of phugoid mode poles varying center pod payload from $0 \mathrm{~kg}$ (square) to $227 \mathrm{~kg}$ (triangle) with $140 \mathrm{~kg}$ shown by the diamond symbol.

The gust model chosen for this paper is based on the DARPA model described above. The gust amplitude at the center of the aircraft is determined by: 


$$
U_{d e}=\frac{U_{r e f}}{2}\left[1-\cos \left(2 \pi \frac{t}{t_{g}}\right)\right]
$$

where $U_{r e f}$ is the reference gust velocity, $t$, is the current time and $t_{g}$ is the gust velocity. Once the derived gust velocity $U_{d e}$ is determined from Eq. (8), the single amplitude gust velocity is calculated using Eq. (2). The gust is applied at 111 nodes along the aircraft wing in UM/NAST model. The gust applied at the i-th node is given by:

$$
U_{\text {gust }}(i)=U_{S A} \cos \left(\frac{x_{i}}{4 \pi}\right)
$$

where $x_{i}$ is the $\mathrm{x}$-coordinate of node $i$. Figure 6 shows a gust distribution for a 2-s duration gust, with a reference gust velocity of $10 \mathrm{~m} / \mathrm{s}$.

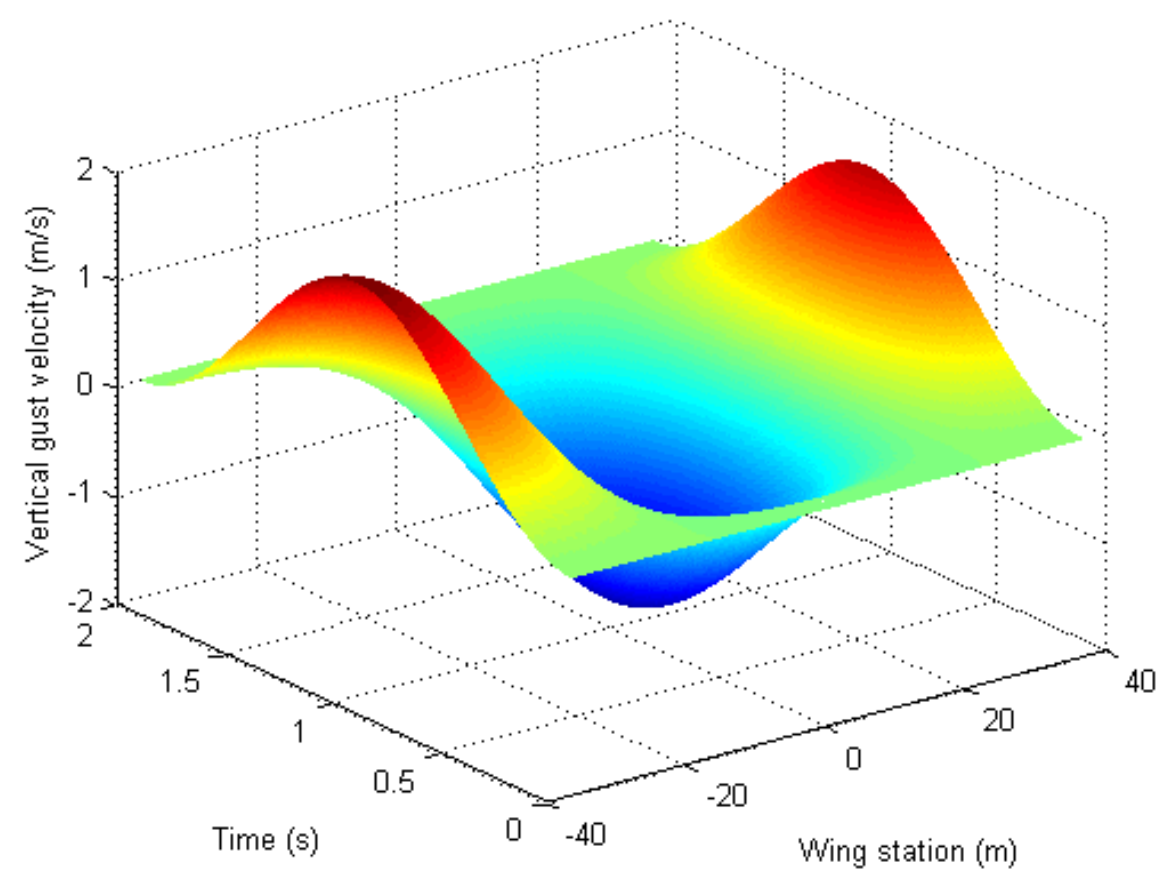

Figure 6. DARPA gust profile.

In order to determine the gust response sensitivity to variations in stiffness properties, the bending, torsional and in-plane bending stiffness values are varied as shown in Table 1. Variations in the extensional stiffness were observed to have virtually no effect on the response, so it was not varied in this study. Originally, the variation was intended to be plus and minus one order of magnitude, but it was found that a limiting stiffness value existed, below which the model was simply too flexible to determine an accurate trim solution. 
Table 1. VFA Model Properties

\begin{tabular}{lll}
\hline \hline & & \\
Parameter & Baseline value & Variation \\
\hline & & \\
Elastic axis & $25 \%$ chord & \\
Center of gravity & $25 \%$ chord & \\
& Stiffness properties & \\
Bending stiffness & 1.03 X $10^{6} \mathrm{~N} \cdot \mathrm{m}^{2}$ & $5 \times 10^{5}-9 \times 10^{6} \mathrm{~N} \cdot \mathrm{m}^{2}$ \\
Torsional stiffness & $1.65 \mathrm{X} \mathrm{10} \mathrm{N} \cdot \mathrm{m}^{2}$ & $3 \times 10^{4}-7 \times 10^{5} \mathrm{~N} \cdot \mathrm{m}^{2}$ \\
In-plane bending stiffness & $1.24 \mathrm{X} 10^{7} \mathrm{~N} \cdot \mathrm{m}^{2}$ & $1 \times 10^{6}-7 \times 10^{7} \mathrm{~N} \cdot \mathrm{m}^{2}$ \\
& Inertia properties & \\
Mass per unit length & $8.93 \mathrm{~kg} / \mathrm{m}$ & \\
Bending mass moment of inertia & $0.69 \mathrm{~kg} \cdot \mathrm{m}$ & \\
Torsional mass moment of inertia & $4.15 \mathrm{~kg} \cdot \mathrm{m}$ & \\
In-plane bending mass moment of inertia & $3.46 \mathrm{~kg} \cdot \mathrm{m}$ & \\
\hline \hline
\end{tabular}

The effects of parameter variations were first examined by creating plots of the phugoid mode poles, which are shown in Figure 7. In each case, all parameters are kept constant at the baseline value with the exception of the parameter being examined, and 140kg is used for the center pod payload. As Figure 7 demonstrates, the stability of the phugoid mode is dependent on the values chosen for the torsional and bending stiffness. Both of these parameters have a limiting value, above which the phugoid mode becomes unstable. Interestingly, the phugoid mode shows the opposite trend when the in-plane bending stiffness is varied. As the stiffness is lowered, the phugoid mode damping becomes more negative, indicating the mode is becoming "more stable."
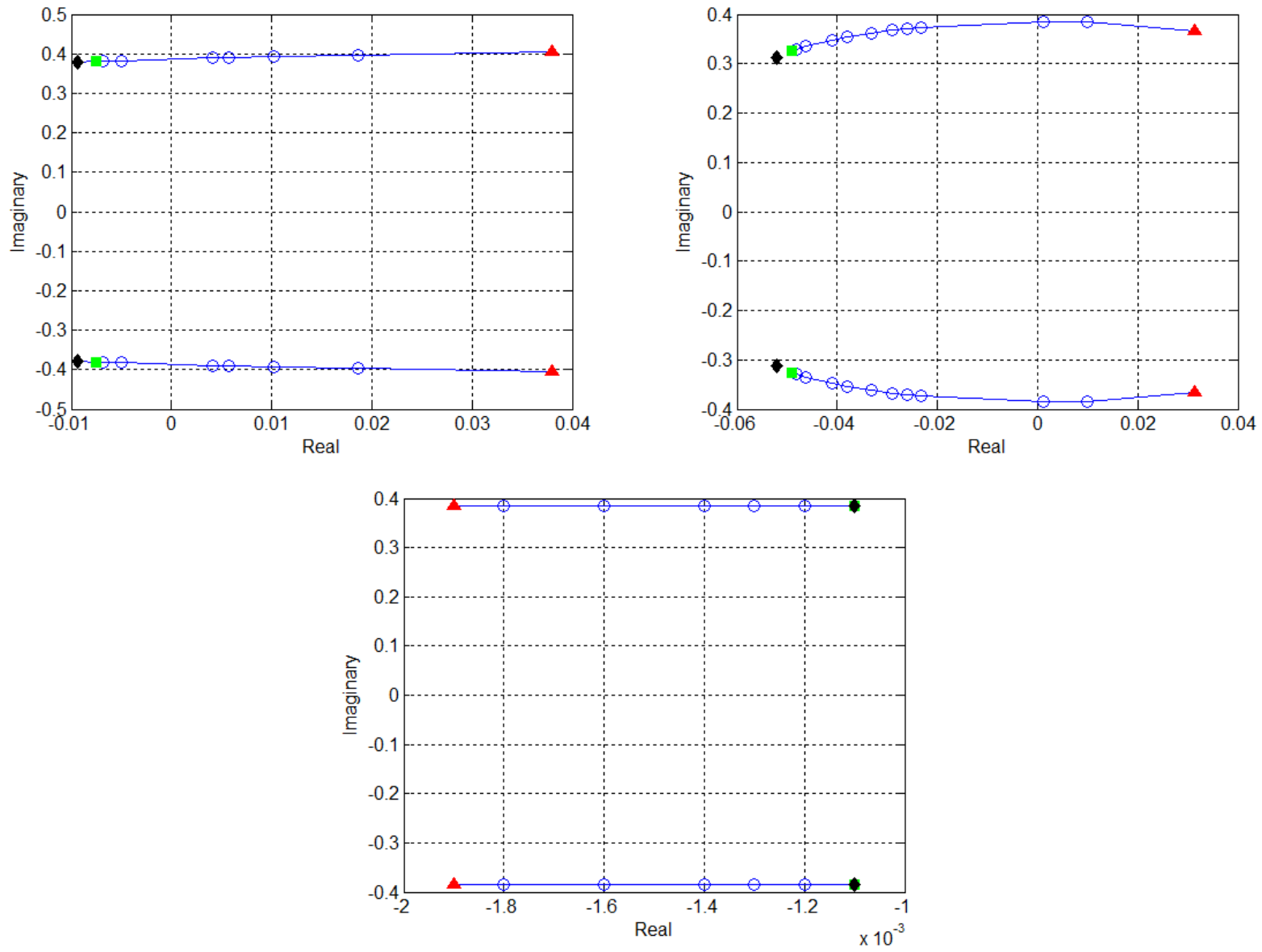

8

American Institute of Aeronautics and Astronautics 
Figure 7. Plot of phugoid mode poles varying stiffness parameters (torsional - top left, bending - top right, inplane bending - bottom) from lower bound (red triangle) to upper bound (green square) to rigid (black diamond).

After the upper and lower bounds were chosen, a method was needed to determine how to optimally space out the twelve simulation cases on the three-dimensional sample space. Latin Hypercube Sampling (LHS) was chosen to maximize the minimum distance between any two points. A matrix of points ranging from zero to one was created by using the MATLAB command "lhsdesign" and running one million simulations. In each case, MATLAB creates a distribution within the sample space, and then after all cases have been run it outputs the case in which the minimum distance between any two points has been maximized. The simulation cases were then generated by multiplying this matrix by the upper and lower bounds, giving the simulation parameters to be used for each case, which are shown in Table 2. The phugoid mode for all cases, with the exception of Model 5, is asymptotically stable, with frequencies ranging from 0.325 to $0.383 \mathrm{rad} / \mathrm{s}$.

Table 2. Simulation model's stiffness parameters.

Bending Stiffness $\left(\mathrm{N} \cdot \mathrm{m}^{2}\right)$

\begin{tabular}{llll} 
Model & Bending & Torsional & In-plane \\
\hline Base & $1.03 \times 10^{6}$ & $1.65 \times 10^{5}$ & $1.24 \times 10^{7}$ \\
1 & $6.93 \times 10^{6}$ & $1.73 \times 10^{5}$ & $1.80 \times 10^{7}$ \\
2 & $2.08 \times 10^{6}$ & $5.11 \times 10^{5}$ & $2.69 \times 10^{7}$ \\
3 & $4.79 \times 10^{6}$ & $0.78 \times 10^{5}$ & $4.51 \times 10^{7}$ \\
4 & $4.35 \times 10^{6}$ & $3.60 \times 10^{5}$ & $6.91 \times 10^{7}$ \\
5 & $0.74 \times 10^{6}$ & $1.14 \times 10^{5}$ & $3.08 \times 10^{7}$ \\
6 & $3.03 \times 10^{6}$ & $2.36 \times 10^{5}$ & $0.77 \times 10^{7}$ \\
7 & $5.82 \times 10^{6}$ & $4.58 \times 10^{5}$ & $1.09 \times 10^{7}$ \\
8 & $7.32 \times 10^{6}$ & $6.18 \times 10^{5}$ & $3.73 \times 10^{7}$ \\
9 & $8.96 \times 10^{6}$ & $4.11 \times 10^{5}$ & $5.95 \times 10^{7}$ \\
10 & $3.11 \times 10^{6}$ & $6.68 \times 10^{5}$ & $5.38 \times 10^{7}$ \\
11 & $1.01 \times 10^{6}$ & $3.00 \times 10^{5}$ & $6.00 \times 10^{7}$ \\
12 & $1.20 \times 10^{6}$ & $6.01 \times 10^{5}$ & $1.50 \times 10^{7}$ \\
\hline \hline
\end{tabular}

\section{E. Open Loop Gust Response}

The gust response of the baseline model was simulated in UM/NAST using the DARPA gust model varying the gust duration and amplitude, starting from the initial trimmed flight at sea level and velocity of $12.2 \mathrm{~m} / \mathrm{s}$. Figure 8 shows the baseline response to gust durations of 2-s, 4-s and 8-s, with a reference gust velocity of $10 \mathrm{~m} / \mathrm{s}$. Even with a reference gust velocity of $10 \mathrm{~m} / \mathrm{s}$, the maximum gust amplitude is roughly $1.8 \mathrm{~m} / \mathrm{s}$ which is much lower than the certification values found in FAR 23. ${ }^{11}$ The maximum value in FAR 23 corresponds to approximately $20 \mathrm{~m} / \mathrm{s}$. The four outputs used in this study are the forward speed, altitude, pitch angle, and curvature about the $y$-axis at the center of the wing, representing where the wing root would be on a conventional aircraft design, which gives a measure of the shape of the wing. Figure 8 shows that as the aircraft encounters a gust of equal amplitude, but longer duration, the response has higher amplitude excursions for all four outputs tracked, with all being asymptotically stable. The duration of the turbulence can be an important factor. In fact, the turbulence that caused the Helios mishap was within limits, but the aircraft was in the turbulence field for longer than on previous flights due to a shallower than normal climb out. ${ }^{2}$ As the gust duration increases, the root curvature remains at a higher value for a longer period of time and takes significantly longer to return to the equilibrium value. Additionally, the aircraft reaches a new equilibrium state for altitude, with the longer duration gusts causing a larger drop in altitude. 

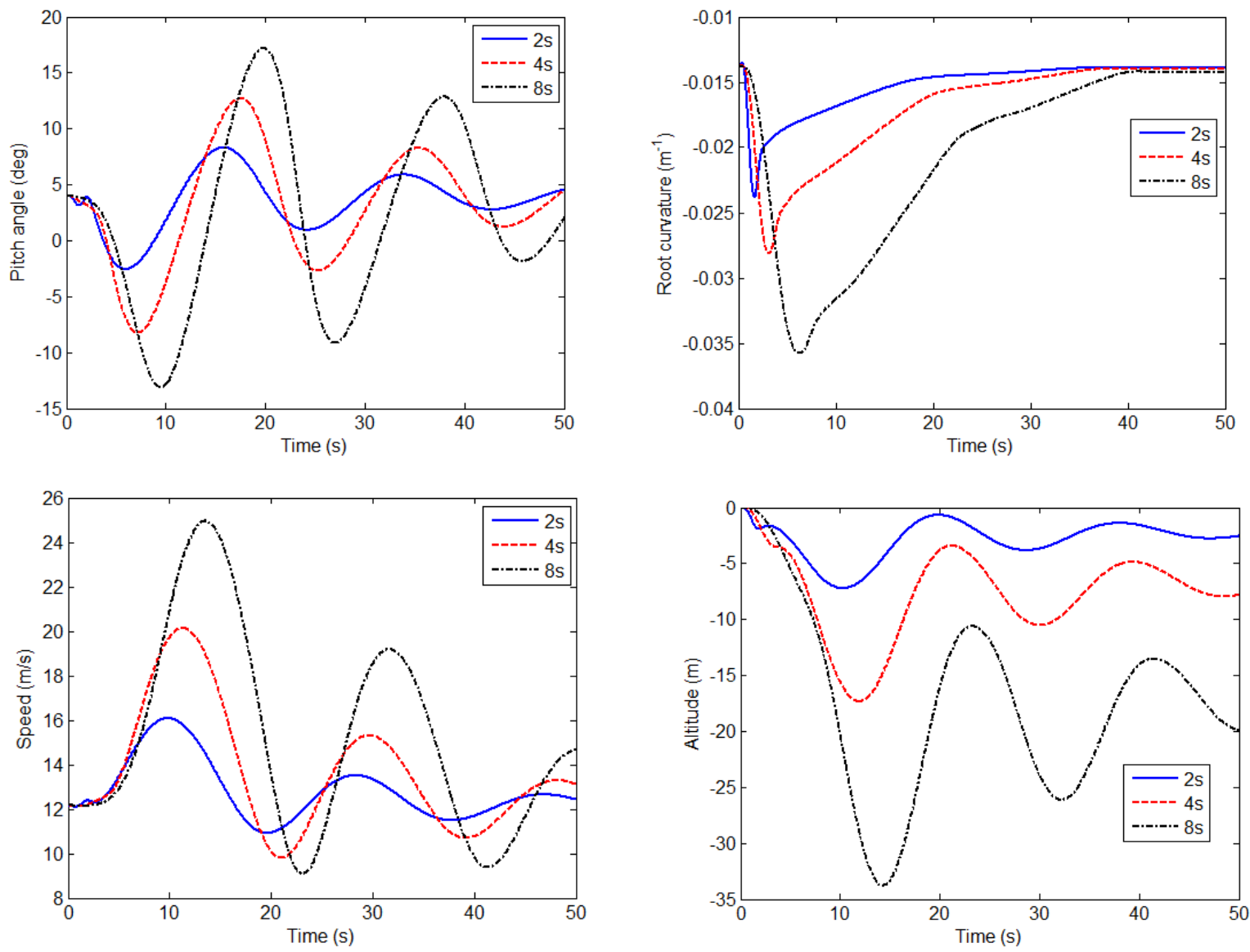

Figure 8. Gust response of baseline model to gust durations of 2-s, 4-s and 8-s with $10 \mathrm{~m} / \mathrm{s}$ reference velocity.

Next, the baseline model was subjected to larger reference gust velocities of $10,20,30$ and $40 \mathrm{~m} / \mathrm{s}$ with gust duration of 2-s. Figure 9 shows that the larger gust amplitudes cause larger aircraft responses. Additionally, the plots show that the gust response is nonlinear. If the system were linear, one would expect the output to scale to the input. For example, the aircraft response to the $20 \mathrm{~m} / \mathrm{s}$ gust would be double that of the $10 \mathrm{~m} / \mathrm{s}$ response. This trend does not show up in these plots. The 20 and $30 \mathrm{~m} / \mathrm{s}$ responses of maximum speed deviation and root curvature roughly scale up linearly, but the $40 \mathrm{~m} / \mathrm{s}$ response does not scale up linearly for any of the four outputs. The speed, curvature and pitch plots show that the $40 \mathrm{~m} / \mathrm{s}$ response is less than the four times the amplification expected in a linear system and are respectively $3.55,3.67$ and 2.91 times the $10 \mathrm{~m} / \mathrm{s}$ plots. The altitude plots show the opposite trend with the nonlinear responses higher than one would expect in a linear system. The 20,30 and $40 \mathrm{~m} / \mathrm{s}$ responses are respectively $2.40,3.86$ and 5.06 times the $10 \mathrm{~m} / \mathrm{s}$ response. Even though the gust disturbances are large, the aircraft states do not leave the domain of attraction of the stable equilibrium, and after the gust has receded, the states converge to the equilibrium. 

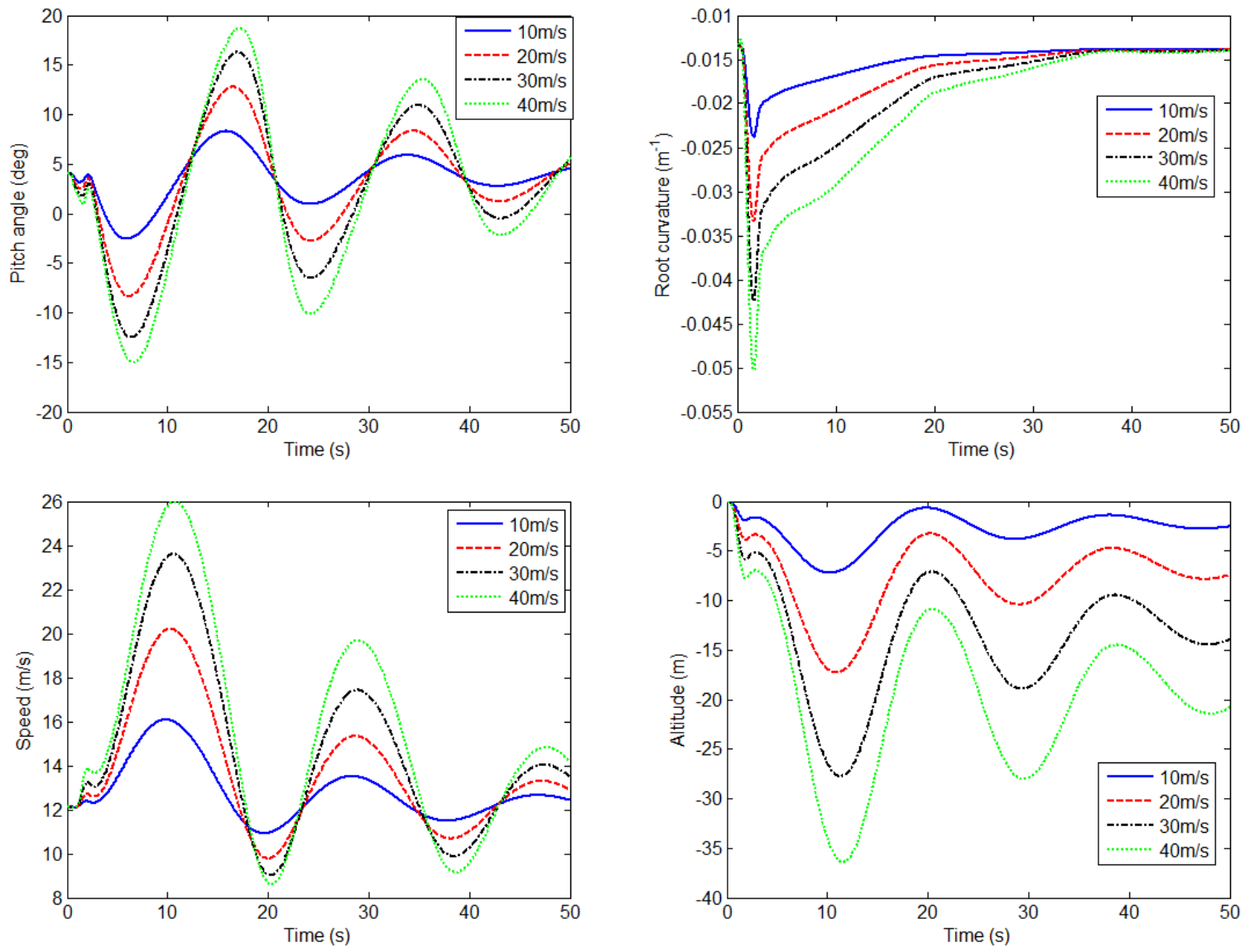

Figure 9. Gust response of baseline model to reference velocities of 10, 20, 30 and 40m/s with 2 s gust duration.

In an effort to determine the effect of varying the stiffness parameters, and therefore the flexible mode frequencies, various open loop gust response metrics are determined as a function of the flexible mode frequencies. Since the phugoid mode frequency is also changing as the stiffness parameters are varied, the gust response metrics are also plotted as a function of the frequency ratios. Linear fits are presented on all plots in order to help determine any trends that are present in the data. In all cases, the gust used has a $10 \mathrm{~m} / \mathrm{s}$ reference velocity and gust durations of 2-s, 4-s and 8-s.

The maximum pitch angle of the aircraft during the gust encounter, as well as the trim pitch angle for the aircraft in still air are shown in Figure 10. The data show that as the phugoid-to- $1^{\text {st }}$ bending ratio, phugoid-to- $1^{\text {st }}$ in-plane bending ratio and $1^{\text {st }}$ torsion-to- $1^{\text {st }}$ in-plane bending frequency ratios increase, the maximum pitch angle decreases. One property of VFA is that they have a phugoid-to- $1^{\text {st }}$ bending frequency ratio near or above one. This indicates that there is a frequency overlap, and therefore likely a coupling between the rigid body and flexible modes. Additionally, as the $1^{\text {st }}$ bending and $1^{\text {st }}$ in-plane bending frequencies increase, the maximum pitch angle decreases. Combining these, it is clear that as the aircraft becomes more flexible, thus causing a higher frequency ratio and a lower frequency of the flexible modes, the maximum pitch angle decreases. These results can be rationalized by noting that as the aircraft becomes more flexible, more of the gust energy goes into the flexible modes and less energy is converted to rigid body pitch angle changes. Also, the data show that increasing the $1^{\text {st }}$ torsion to $1^{\text {st }}$ inplane bending frequency ratio causes a decrease in maximum pitch angle. It should also be noted that other frequencies and frequency ratios, such as phugoid-to- $1^{\text {st }}$ torsion ratio, $1^{\text {st }}$ bending-to- $1^{\text {st }}$ in-plane bending ration and $1^{\text {st }}$ torsional frequency were also examined, but the data were scattered and showed no real trend. 

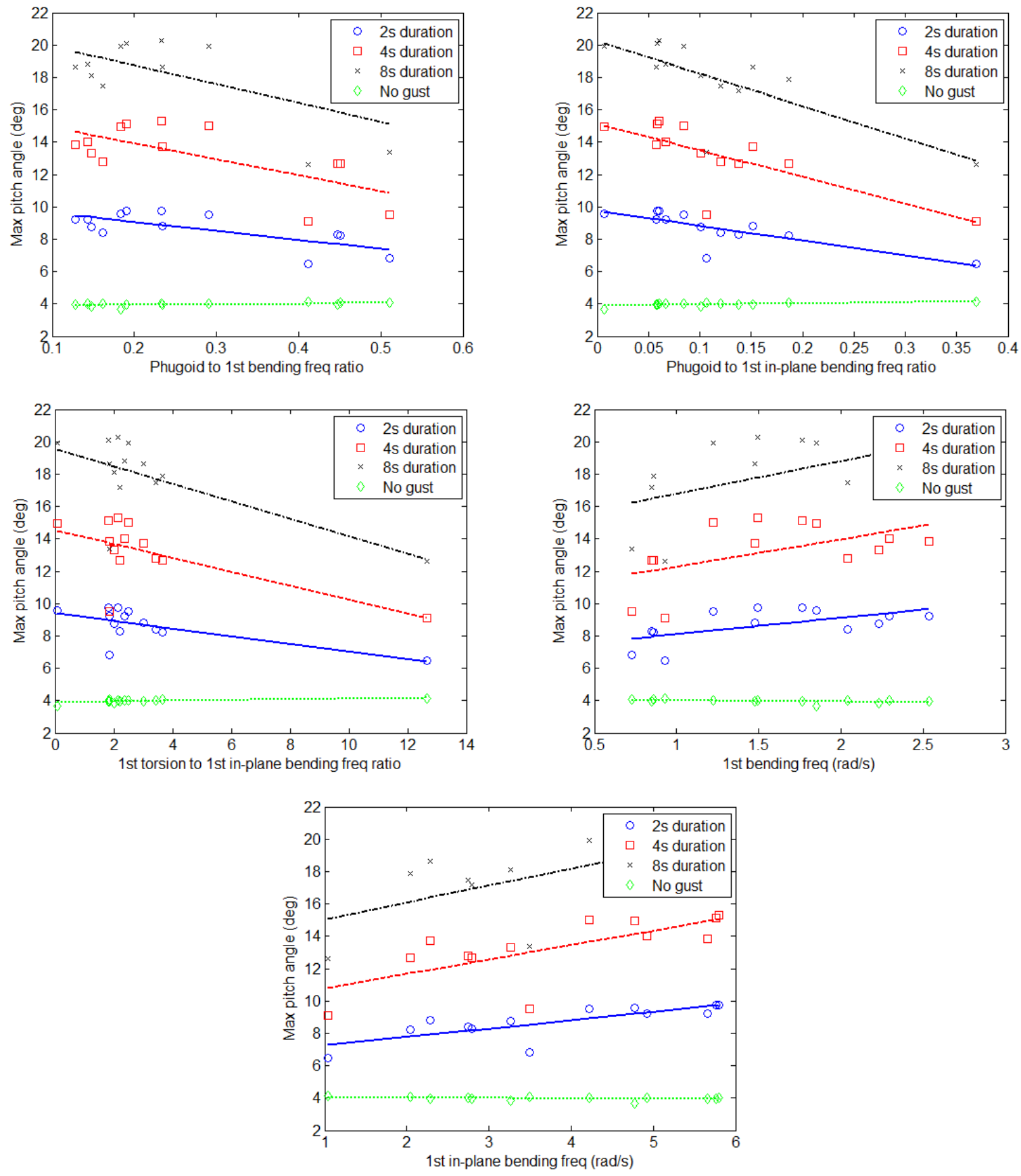

Figure 10. Maximum pitch angle.

The maximum root curvature of the wing resulting from the gust encounter was then examined. The data tends to be more scattered than the maximum pitch angle and most plots showed no discernible trends. The two exceptions are the maximum root curvature versus phugoid-to- $1^{\text {st }}$ bending frequency ratio and the maximum root curvature versus $1^{\text {st }}$ bending frequency plots which are shown in Figure 11. The plots show that as the wing becomes more flexible in the bending direction, a higher root curvature is observed. This trend can also be seen in the trimmed values, with the more flexible models having a higher trim curvature. These observations are in direct conflict with the maximum pitch angle results. It is reasonable to believe that aircraft designers, for most applications, would be more concerned with minimizing wing curvatures and therefore, in the absence of any additional information, would tend to choose the less flexible models and accept the penalty of a larger maximum 
pitch angle in the presence of gust. Note that at high altitudes pitch deviations may present less of a safety of flight risk than large deformations of the wings.
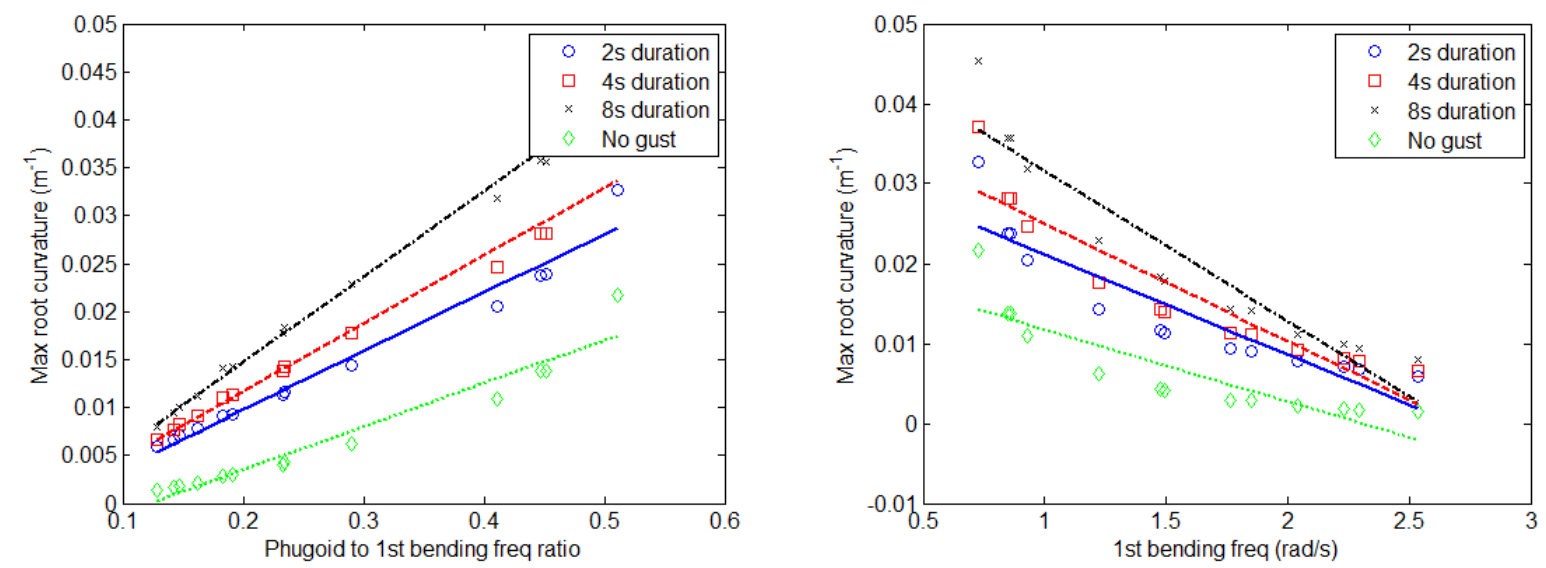

Figure 11. Maximum root curvature.

To further illustrate the reciprocal relationship between the maximum pitch angle and the maximum curvature of the aircraft models in a gust field, the maximum pitch angle is plotted versus the maximum curvature in Figure 12. It is evident in the plot that a higher maximum pitch angle is obtained in the models with the lowest curvature value. Note the wide range of trimmed curvatures, indicating a significant difference in the trimmed shape of the aircraft while the trimmed pitch angle stays relatively constant.

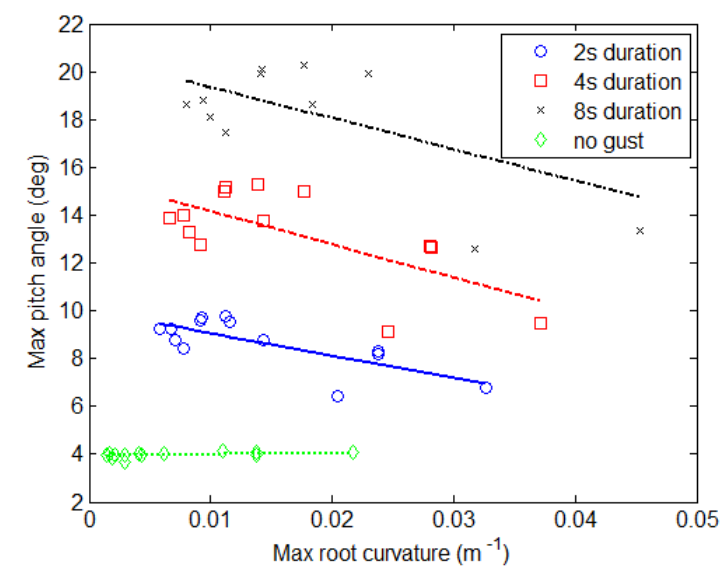

Figure 12. Maximum wing curvature versus maximum pitch angle.

\section{F. Closed Loop Gust Response}

During the flight the aircraft will be under closed-loop control, therefore the closed-loop characteristics and responses to gust are now examined. In order to investigate various closed loop performance metrics, $20^{\text {th }}$-order linear models were obtained from the nonlinear simulations using system identification. The linear models are extracted using the MATLAB system identification toolbox applied to data obtained from simulations of UM/NAST. In all cases the gust inputs used were the same as used in Figure 8 for the baseline model as well as 3 50 -s sine sweeps with beginning frequencies ranging from $0.05-0.11 \mathrm{~Hz}$ and final frequencies ranging from $0.06-$ $0.39 \mathrm{~Hz}$. The elevator and aileron models were identified using doublets with periods of 1-s and 5-s. The models have three control inputs: the elevators constrained to move together, as well as the two ailerons which are free to move independently of each other. The decision was made to use a $20^{\text {th }}$ order model as a tradeoff between nonlinear model matching and the desire to obtain the lowest order linear model possible. For all the aircraft models, which correspond to different stiffness values, several different state space models are created with the best linear model chosen for each to match the nonlinear solution with the means removed from the data. At first, there was some difficulty matching the curvature data, due to their relatively small values compared to the other outputs. To address 
this, the curvature outputs are multiplied by 100 , which puts their value close to unity, the identification performed, and then the bias removed from the resulting $C$-matrix. A comparison of the nonlinear and linear models for the baseline aircraft are shown in Figure 13.
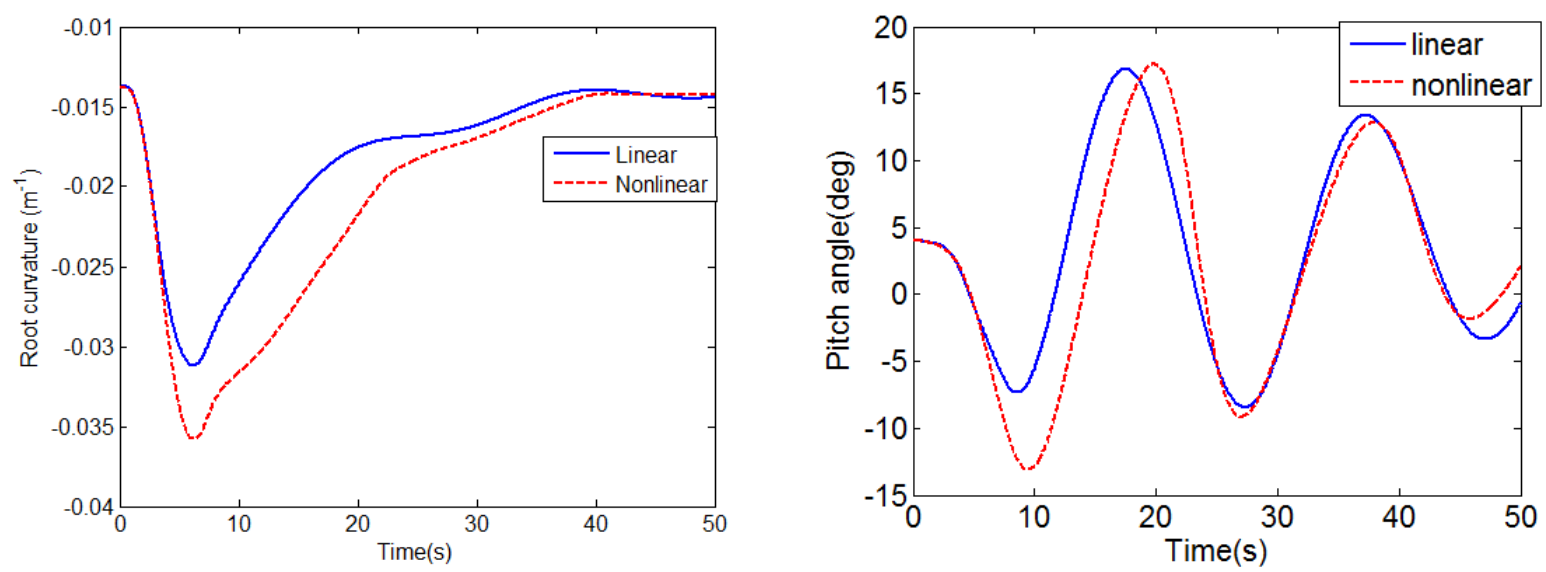

Figure 13. Comparison between linear (blue) and nonlinear (red-dashed) data for baseline case subjected to $10 \mathrm{~m} / \mathrm{s}$ gust reference velocity and $8 \mathrm{~s}$ duration.

The output control effort was calculated based on Eq. (7) to drive the system from an initial pitch angle of $0^{\circ}$ to a final output of $10^{\circ}$. The data, excluding points for Model 1 from Table 2 because it was a significant outlier, are normalized to the largest output control effort and are plotted in Figure 14. Despite the scatter in the data, several trends can be observed. Specifically, the output control effort increases as the bending stiffness decreases. This is reasonable given that more of the energy fed into the system is absorbed by the flexible modes as the stiffness decreases. Additionally, the data show that the output control effort is proportional to the phugoid-to- ${ }^{\text {st }}$ in-plane bending frequency ratio and decreases with an increase in the $1^{\text {st }}$ bending-to- $1^{\text {st }}$ torsion frequency ratio.
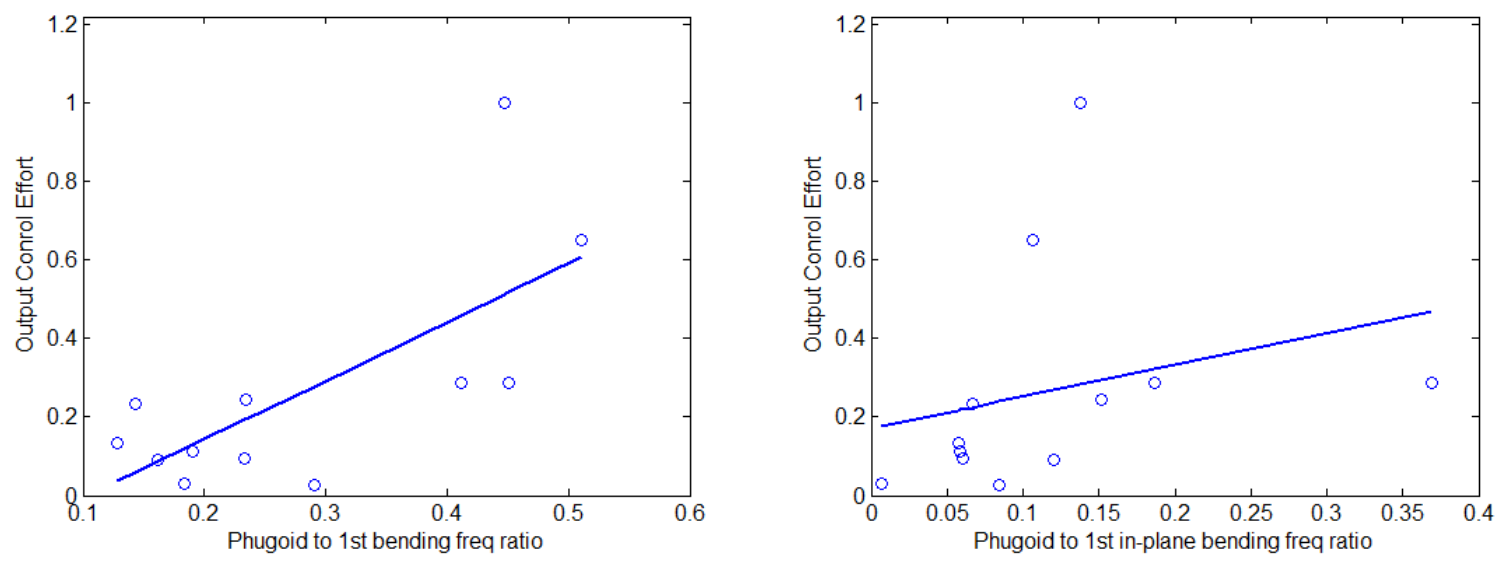

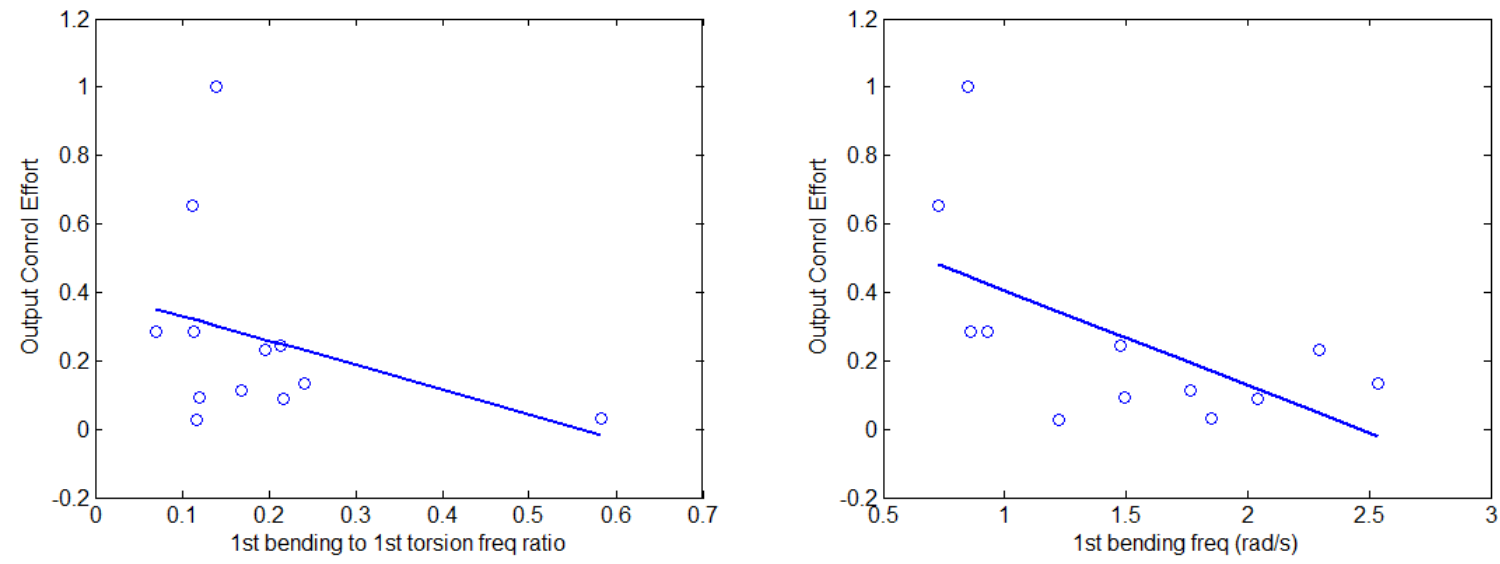

Figure 14. Output control effort required from pitch angle of $0^{\circ}$ to $10^{\circ}$.

The closed-loop response to a $2^{\circ}$ pitch step input command in the presence of a 2 -s duration gust was then calculated using linearized models and an LQG controller. The LQG controller was designed with an integrator added on pitch angle. State cost is applied to all outputs, with the cost of the pitch angle half the cost of the other outputs. The controller gains are first tuned to minimize the overshoot and settling time of the pitch angle response based on the baseline model simulations. Once acceptable performance was obtained for the baseline model, based on Ref [20], separate LQG controllers are designed for other models in Table 2 using the same state and control weights as for the baseline model. The time history for the models with the highest and lowest overshoot is shown in Figure 15. When the simulations are run without the gust present, all the models match the command almost exactly, although some are over-damped. Additionally, for all of the controllers used in this study, no actuator dynamics are included and no limits imposed on the deflection of the control surfaces. These additional factors will be examined in a later paper.

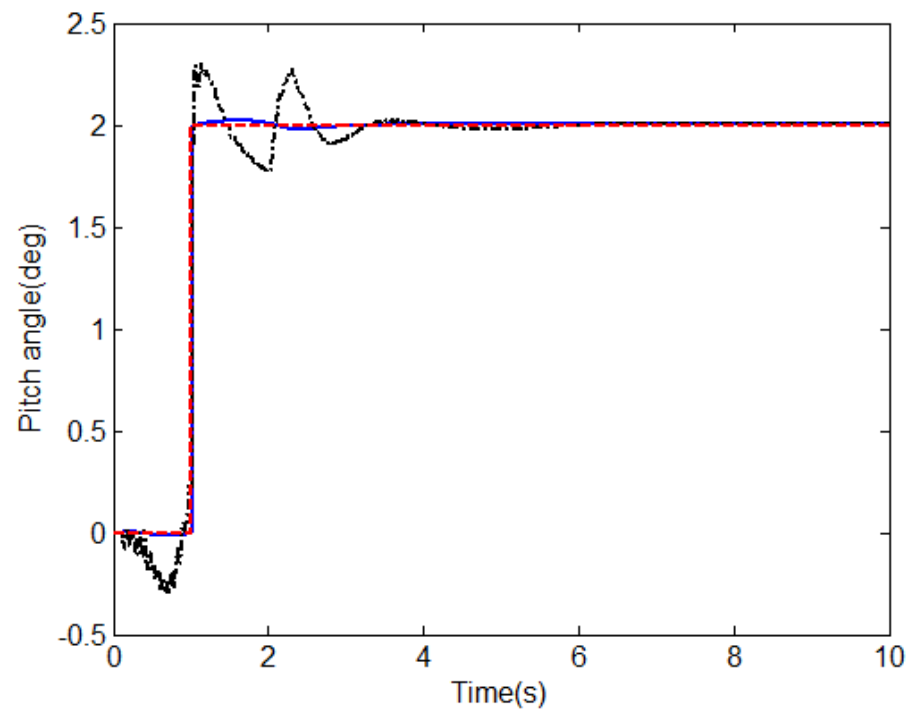

Figure 15. Time plots for lowest (blue) and highest (black dash-dot) overshoot to $2^{\circ}$ step command (red dash) in presence of 2-s duration gust.

The first parameter examined is the maximum overshoot, seen in Figure 16. There are several trends apparent in the linear fits of the data, although the data are fairly scattered. The plots show the least amount of overshoot as the models become more flexible in bending and stiffer in torsion and in-plane bending, respectively. The plots also show good performance by all the models, with the maximum overshoot at roughly $15 \%$ of the command. 

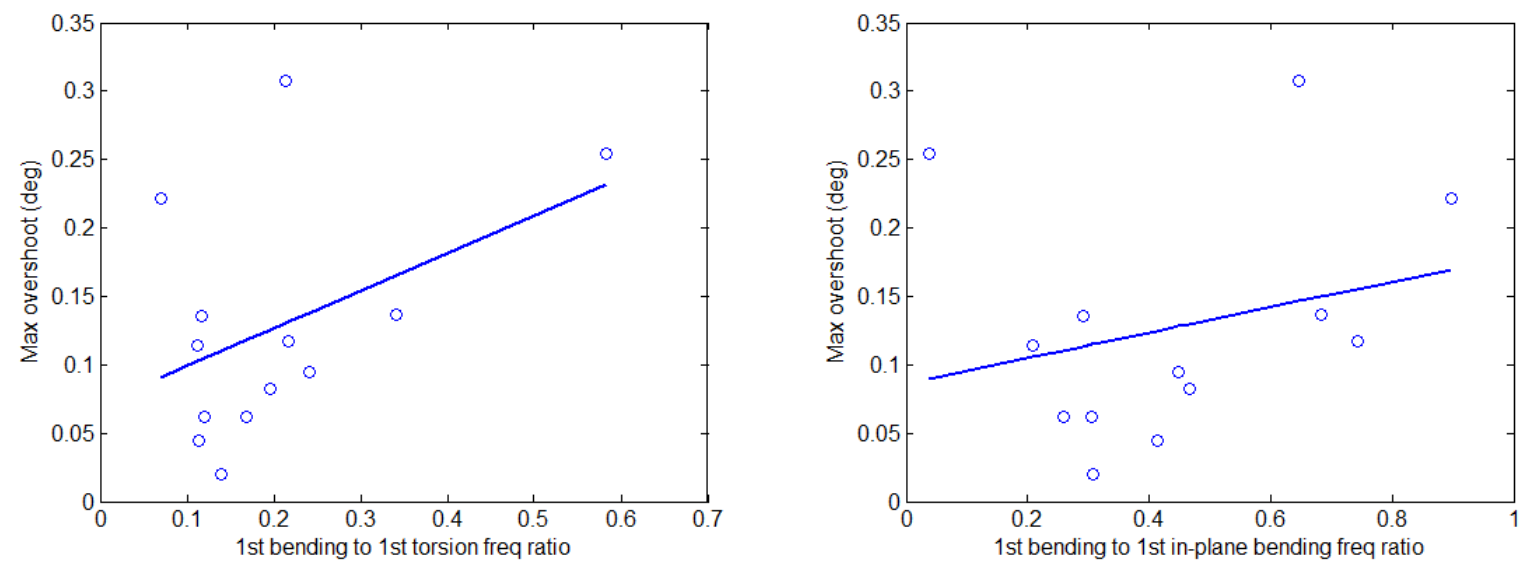

Figure 16. Maximum overshoot in pitch angle to a $2^{\circ}$ pitch command using LQG control.

Next, the settling time was calculated for all the models in response to the same $2^{\circ}$ pitch angle step command and the results are shown in Figure 17. The settling time is based on the response entering, and staying within $2 \%$ of the step command. The settling time decreases as the ratio of the phugoid to all three frequency ratios increases. Additionally, the settling time increases with the $1^{\text {st }}$ bending frequency. These results show that the more flexible the aircraft, the longer the settling time.
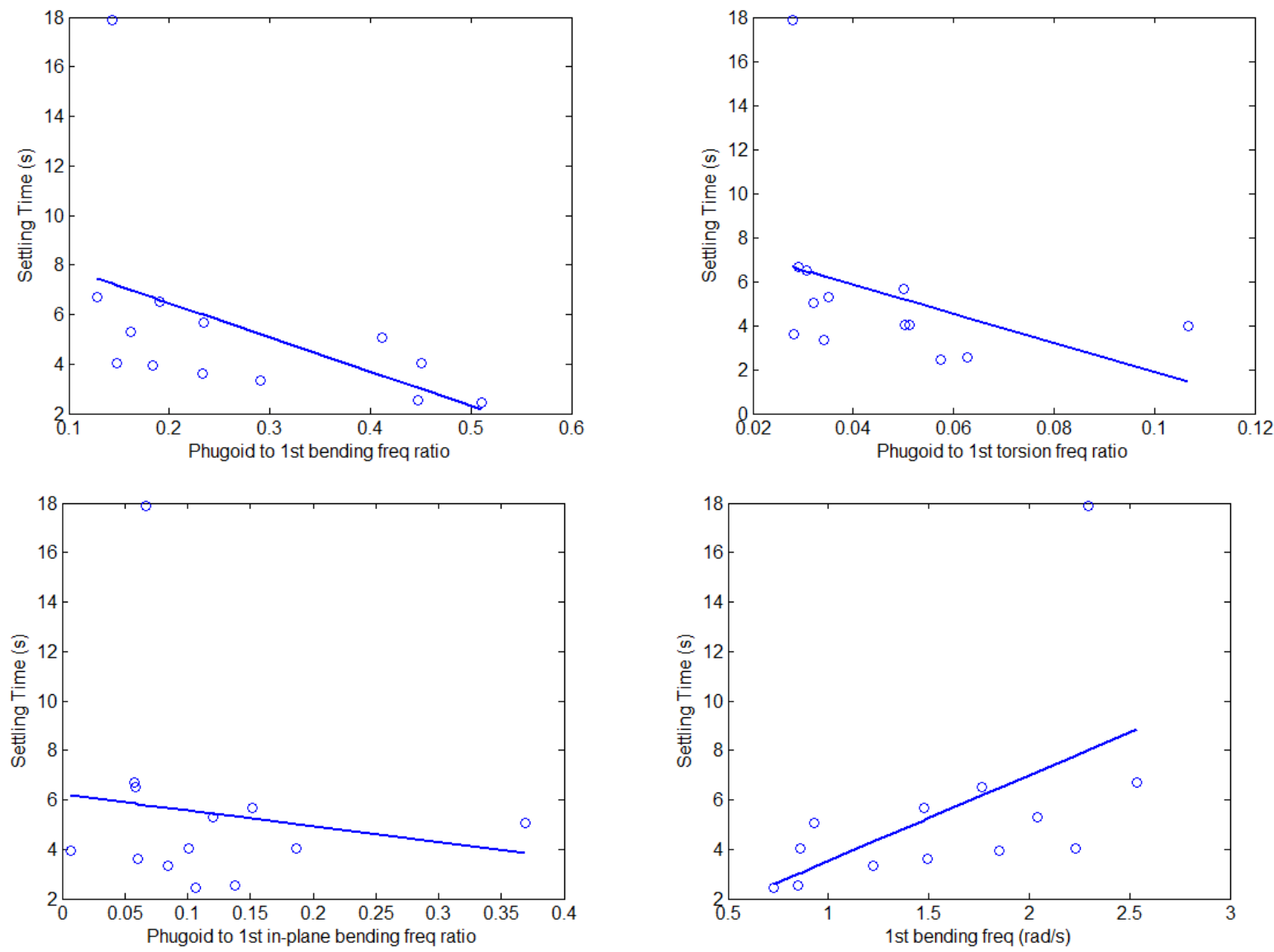

Figure 17. Settling time of pitch angle response to a $2^{\circ}$ pitch command using LQG control. 
We have also investigated the ability of the controller to regulate pitch command to $0^{\circ}$ in the presence of a 2-s duration gust. This gives a measure of how well an LQG controller can hold the aircraft flying straight and level while encountering gust. The resulting plots of maximum pitch angle excursion are shown in Figure 18. The plots are similar to those in Figure 16, with the same trends showing up in the plots.
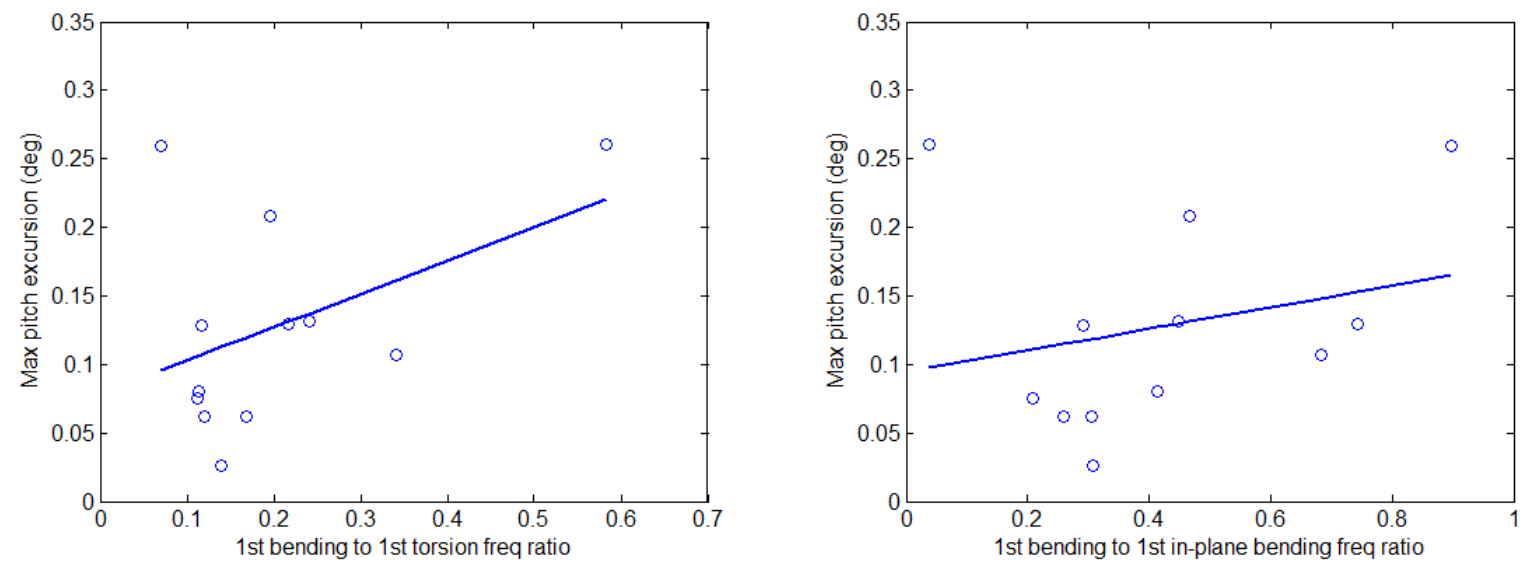

Figure 18. Maximum overshoot to a $0^{\circ}$ pitch command using LQG control.

Additionally, the settling time for the models using an LQG controller to follow a $0^{\circ}$ pitch command while encountering a 2-s duration gust is shown in Figure 19. The settling time is defined as the time when the pitch angle enters and remains in the bound of plus/minus $0.01^{\circ}$. The plots confirm similar trends to those in Figure 17. The first three plots show that as the ratio of the phugoid to flexible frequencies increase, indicating the aircraft is stiffer, the settling time decreases.
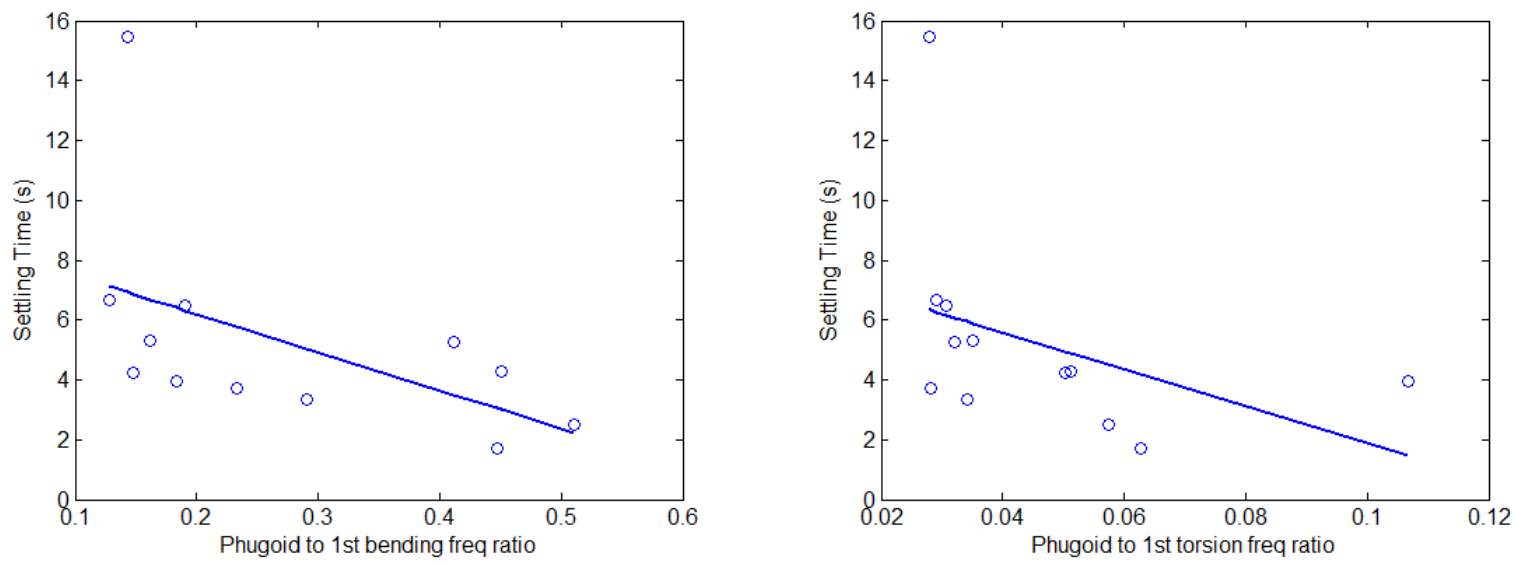

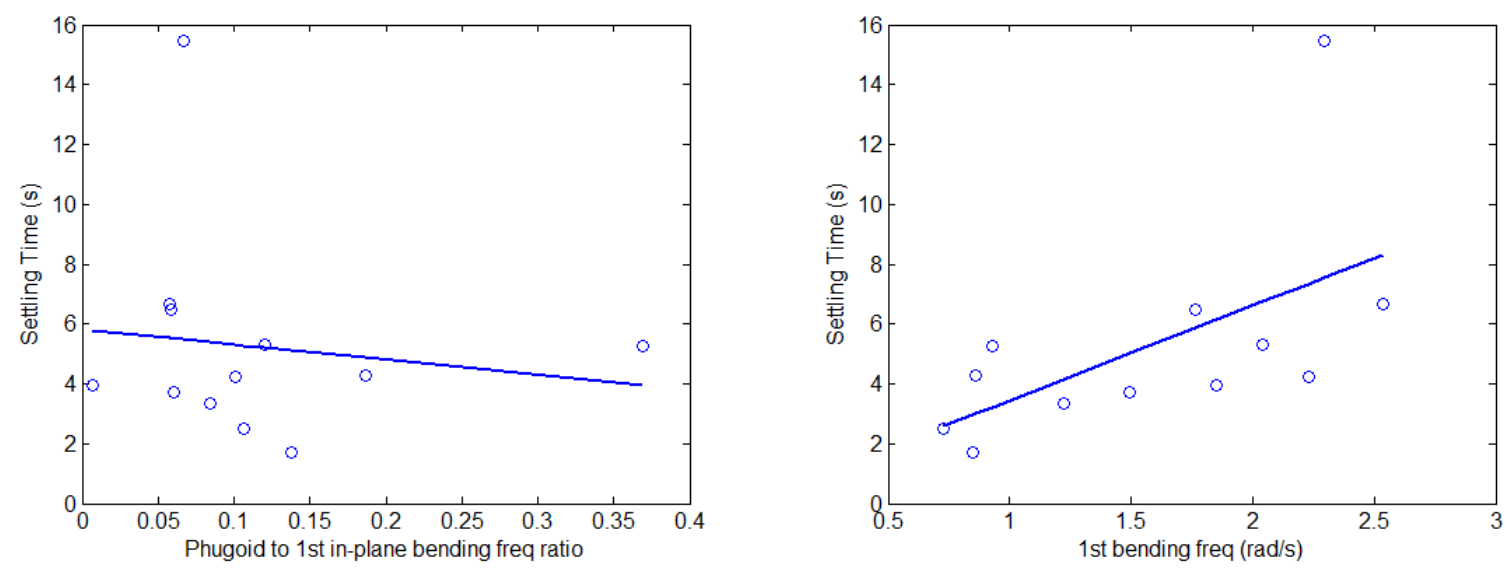

Figure 19. Settling time to a $0^{\circ}$ pitch command using LQG control.

Finally, we compare the open loop gust response of the linearized models to the response of the closed loop system with a $0^{\circ}$ pitch angle command and in the presence of gust. An additional integrator on root curvature is added to the LQG to more effectively reduce the maximum root curvature caused by the gust, and the state weighting for the pitch angle and root curvature is reversed from the previous controller. The maximum root curvature of the open loop linearized system was compared to the maximum curvature of the closed loop system with integrator added to pitch angle only, denoted as controller 1, and closed loop system with integrators on both root curvature and pitch angle, denoted as controller 2 , with a $0^{\circ}$ pitch command, with gust durations of 2-s, 4-s and 8 -s. The additional integrator is needed in controller 2 because in some cases, controller 1 produced a root curvature much larger than the open loop system. Figure 20 illustrates this point by showing the open loop as well as closed loop with both controller 1 and controller 2 for Model 5 in a 2-s gust. While controller 2 performs better at reducing the root curvature, there is a small increase in maximum pitch angle over controller 1 values. The maximum curvature is reduced from the linearized, open loop system by $12 \%$ for the 2-s duration, $29 \%$ for the 4 -s duration and $61 \%$ for the 8 -s duration using controller 2 . This controller performs better at reducing the curvature for the longer duration gusts because the gust onset is slower for these longer duration gusts.
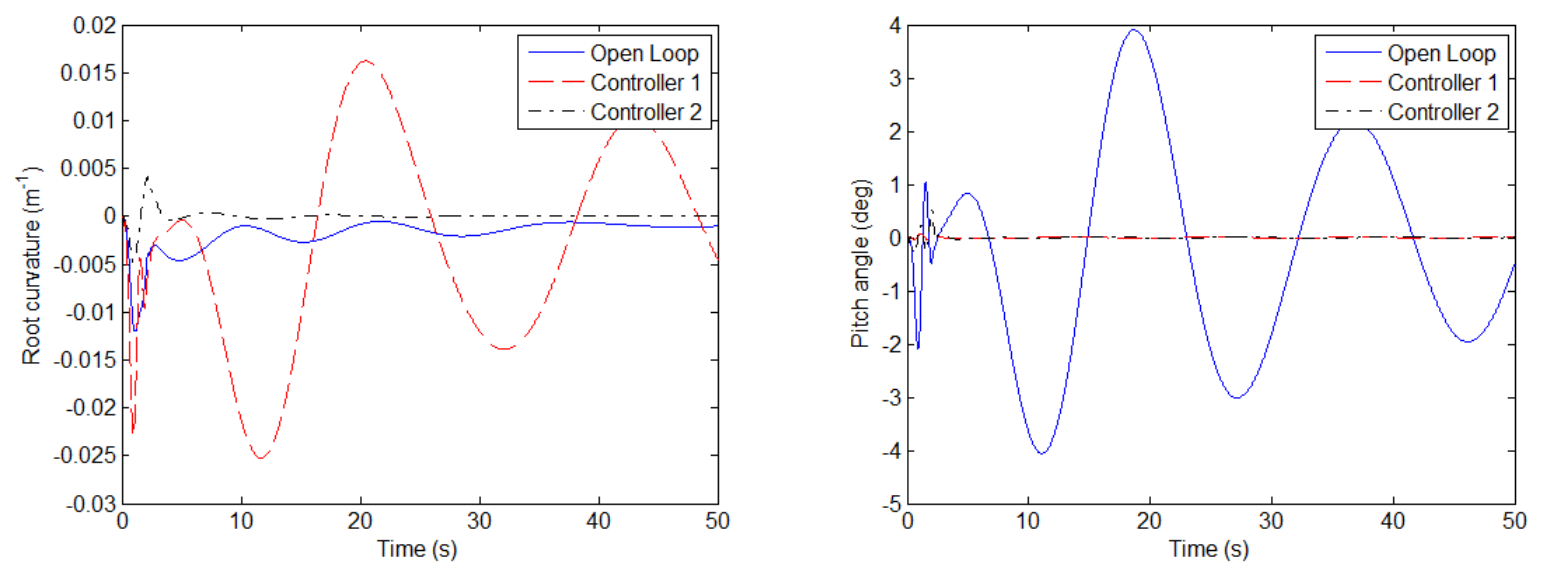

Figure 20. Comparison of open and closed loop performance with controllers 1 and 2 of Model 5 with 2-s durations gust.

Controller 2 was then used to assess the abilities of the aircraft to follow the $2^{\circ}$ pitch step command. Overall, the models show a much higher overshoot than using controller 1, but are significantly more effective at reducing the root curvatures. Figure 21 shows the response of Model 5 to the $2^{\circ}$ pitch command in the presence of the 2-s gust. In this example, the maximum curvature is reduced by roughly a factor of 10 , while the maximum overshoot is 3 times higher. 

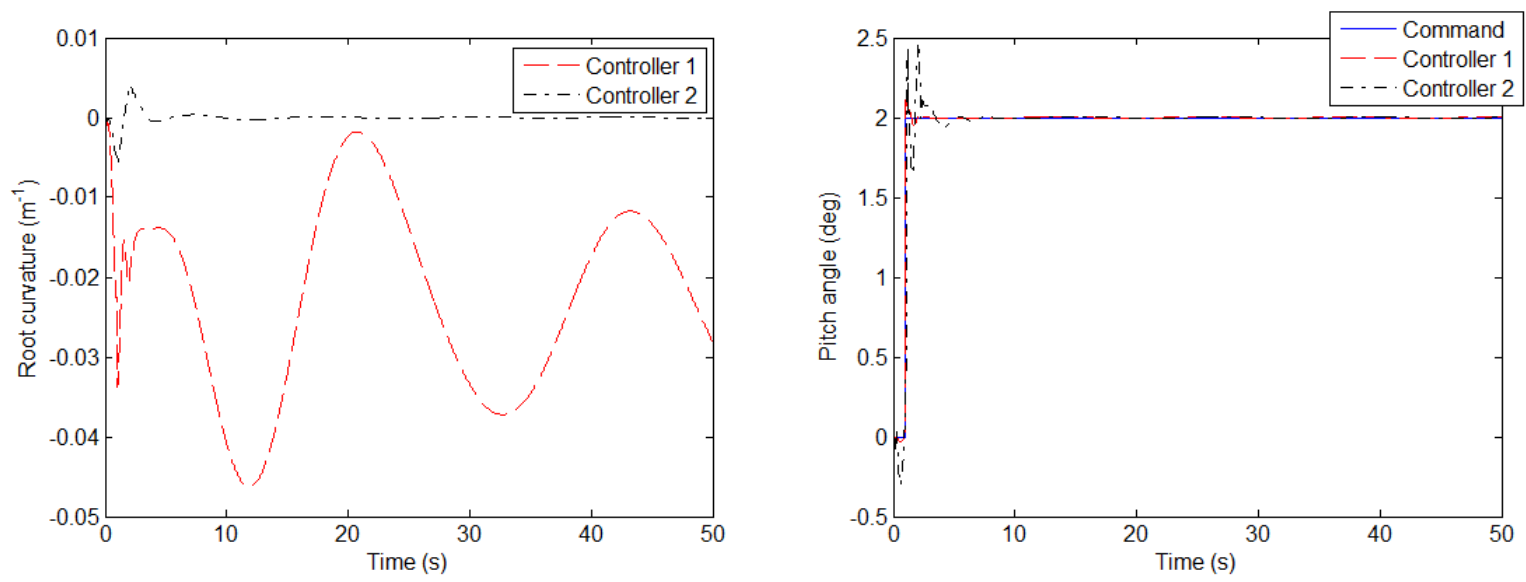

Figure 21. Comparison of root curvature and pitch angle response to a $2^{\circ}$ pitch step command using controllers 1 and 2 in the presence of a 2 -s duration gust.

\section{Concluding Remarks}

The gust response of VFA is a very important area of study. As was the case with Helios, gusts can cause significant perturbations to aircraft dynamics leading to instability. Through the use of a representative baseline VFA model, response to varying amplitudes and durations of gust was studied. The response of the baseline aircraft to gusts of differing amplitudes was found to be nonlinear. Specifically, the pitch angle, speed and curvature excursions were less than one would expect scaling up the $10 \mathrm{~m} / \mathrm{s}$ response linearly, while the altitude was more than expected based on linear scaling. It was also shown that the longer the aircraft is in the gust field, the larger is the response, even while the gust amplitude is held constant.

The bending, in-plane bending and torsional stiffness were then varied to determine the sensitivity to parameter variation of gust response. Twelve models, in addition to the baseline model, were simulated encountering a gust field with reference amplitude of $10 \mathrm{~m} / \mathrm{s}$ and gust durations of 2-s, 4-s and 8-s. The response was then examined as a function of various frequency ratios and the frequencies themselves. The maximum pitch angle excursion was found to decrease with the increase in both the bending and in-plane bending frequencies and increase proportionally to the ratio of the phugoid frequency to these two frequencies. Additionally the maximum pitch angle excursion during a gust encounter was found to be highly dependent on the ratio of the $1^{\text {st }}$ torsion-to- $1^{\text {st }}$ inplane bending frequency. The maximum root curvature was found to be a function of the $1^{\text {st }}$ bending frequency as well as the ratio of the phugoid-to- $1^{\text {st }}$ bending frequency. The trends for the maximum curvature were the exact opposite of those for maximum pitch angle.

Finally, the output controllability and closed loop responses of $20^{\text {th }}$-order linearized models derived using system identification were investigated. The output control effort required to drive the systems from a pitch angle of $0^{\circ}$ to a final pitch angle of $10^{\circ}$ was found to be a function of the bending and in-plane bending frequencies as well as the $1^{\text {st }}$ torsion to $1^{\text {st }}$ bending frequency ratio. In general stiffer models, as well as those with smaller bending to torsion ratios, were found to require lower output control efforts, indicating they may be easier to control. The maximum overshoot and settling time in response to a $2^{\circ}$ pitch angle step command in the presence of gust using an LQG controller was calculated. The overshoot was found to be a proportional to the $1^{\text {st }}$ bending-to- $1^{\text {st }}$ torsion and $1^{\text {st }}$ bending-to- $1^{\text {st }}$ in-plane bending frequency ratios. The settling time plots show that the more flexible the models are, the longer the settling time. The models were then given a $0^{\circ}$ pitch angle command while encountering the gust to determine their ability to maintain level flight. The results for maximum pitch deviation and settling time are very similar to the $2^{\circ}$ step case with the exception of the $1^{\text {st }}$ torsional frequency, which does not seem to play a role. While the original controller performed well at regulating pitch angle, it did a poor job at minimizing root curvature values. An additional integrator was added on root curvature, which reduced root curvature values due gust by up to $61 \%$ when compared to the open loop linearized model. This new controller then demonstrated excellent root curvature reduction and adequate pitch control when tracking a $2^{\circ}$ pitch angle step command.

Overall, with the exception of open loop pitch angle performance, the stiffer models perform better both in open and closed loop, but when dealing with VFA designing a stiffer airplane in bending is not an option. However, this study shows there may be other options involving the torsional and in-plane bending stiffness that are available to 
the designer to improve performance. Additionally other trends may warrant further investigation. For example, the open loop pitch angle response seems to be very dependent on the ratio of the $1^{\text {st }}$ torsion-to- $1^{\text {st }}$ in-plane bending frequencies. Overall, the in-plane bending frequency variation plays a large role in response.

\section{References}

${ }^{1} \mathrm{Su}$, W. and Cesnik, C.E.S., "Dynamic Response of Highly Flexible Flying Wings," AIAA Journal, Vol. 49, No. 2, February 2001, pp. 324-339.

${ }^{2}$ Noll, T.E., Brown, J.M., Perez-Davis, M.E., Ishmael, S.D., Tiffany, G.C., and Gaier, M., "Investigation of the Helios Prototype Aircraft Mishap,” January 2004.

${ }^{3}$ Patil, M. J., Hodges, D. H., and Cesnik, C. E. S., "Nonlinear Aeroelasticity and Flight Dynamics of High-Altitude Long Endurance Aircraft," Journal of Aircraft. Vol. 38, No. 1 Jan. - Feb. 2001.

${ }^{4}$ Su, W., and Cesnik, C. E. S., "Dynamic Response of Highly Flexible Flying Wings," AIAA Journal, Vol. 49, No. 2, February 2011, pp.324-339.

${ }^{5}$ Palacios, R., and Cesnik, C.E.S., "Structural Models for Flight Dynamic Analysis of Very Flexible Aircraft," 50 ${ }^{\text {th }}$ AIAA/ASME/ASCE/AHS/ASC Structures, Structural Dynamics, and Materials Conference, 4-7 May 2009, Palm Springs, CA.

${ }^{6}$ Shearer, C.M., and Cesnik, C.E.S., "Nonlinear Flight Dynamics of Very Flexible Aircraft," Journal of Aircraft, Vol.44, No.5, 2007, pp. 1528-1545.

${ }^{7}$ Layton, J.B., "An Examination of the Gust Response of a Finite Span Wing with Respect to Structural and Geometric Properties, AIAA-95-1375-CP.

${ }^{8}$ Dillsaver, M.J, Cesnik, C.E.S and Kolmanovsky, I.V., "Gust Load Alleviation Control for Very Flexible Aircraft," AIAA Guidance, Navigation and Control Conference, 8-11 August 2011, Portland, OR.

${ }^{9}$ Gibson, T.E., Annaswamy, A.M. and Lavretsky, E., "Modeling for Control of Very Flexible Aircraft," AIAA Guidance, Navigation and Control Conference, 8-11 August 2011, Portland, OR.

${ }^{10}$ Hoblit, F.M., Gust Loads on Aircraft: Concepts and Applications, AIAA Education Series, Washington, D.C., 1988.

${ }^{11}$ anon, Federal Aviation Regulation 23, Federal Aviation Administration, United States of America.

${ }^{12}$ anon, Vulture II Broad Agency Announcement, Defense Advanced Research Projects Agency, DARPA-BAA-10-04, October 16, 2009.

${ }^{13} \mathrm{Su}, \mathrm{W}$., "Coupled Nonlinear Aeroelasticity and Flight Dynamics of Fully Flexible Aircraft," Ph.D. Dissertation, University of Michigan, Ann Arbor, MI, 2008.

${ }^{14}$ Peters, D.A. and Johnson, M.J., "Finite State Airloads for Deformable Airfoils on Fixed and Rotating Wings," Proceedings of Symposium on Aeroelasticity and Fluid/Structure Interaction/Proceedings of the Winter Annual Meeting, Fairfield, NJ, 1994.

${ }^{15}$ Williams, R.L. and Lawrence, D.A., Linear State-Space Control Systems, John Wiley \& Sons, Inc., Hoboken, NJ, 2007.

${ }^{16}$ Skelton, R.E., Dynamic Systems and Control: Linear Systems Analysis and Synthesis, John Wiley and Sons, Inc., New York, 1988.

${ }^{17}$ Kreindler, E. and Sarachik, P.E., "On the Concepts of Controllability and Observability of Linear Systems," IEEE Transactions on Automatic Control, Vol. 9, Issue 2, pp. 129-136.

${ }^{18}$ Skogestag, S. and Postlethwaite, I., Multivariable Feedback Control Analysis and Design, John Wiley and Sons, 2005.

${ }^{19}$ Maddi, A., Guessoum, A., and Berkani, D., "Using Linear Quadratic Gaussian Optimal Control for Lateral Motion of Aircraft," World Academy of Science, Engineering, and Technology, 49, 2009.

${ }^{20}$ Patil, M.J., and Hodges, D.H., "Flight Dynamics of Highly Flexible Flying Wings," International Forum on Aeroelasticity and Structural Dynamics, 2005, Munich, Germany, June 28 - July 1, 2005. 